\title{
Improved impedance to maladaptation and enhanced VCAM-1 upregulation with resistance-type training in the long-lived Snell dwarf (Pit1 $\left.{ }^{d w / d w}\right)$ mouse
}

\author{
Erik P. Rader ${ }^{1}$, Marshall A. Naimo ${ }^{1,2}$, James Ensey ${ }^{1}$, Brent A. Baker ${ }^{1}$ \\ ${ }^{1}$ Centers for Disease Control and Prevention, National Institute for Occupational Safety and Health, Morgantown, \\ WV 26505, USA \\ ${ }^{2}$ West Virginia School of Medicine, Division of Exercise Physiology, Morgantown, WV 26506, USA
}

Correspondence to: Erik P. Rader; email: wlz4@cdc.gov

Keywords: skeletal muscle, stretch-shortening contractions, plantarflexor muscles

Received: December 11, 2019 Accepted: January 27, $2022 \quad$ Published: February 3, 2022

Copyright: (C) 2022 Rader et al. This is an open access article distributed under the terms of the Creative Commons Attribution License (CC BY 3.0), which permits unrestricted use, distribution, and reproduction in any medium, provided the original author and source are credited.

\begin{abstract}
Snell dwarf mice with the Pit1 ${ }^{d w / d w}$ mutation are deficient in growth hormone, prolactin, and thyroid stimulating hormone and exhibit $>\mathbf{4 0 \%}$ lifespan extension. This longevity is accompanied by compromised muscular performance. However, research regarding young (3-month-old) Snell dwarf mice demonstrate exceptional responsivity to resistance-type training especially in terms of a shifted fiber type distribution and increased protein levels of vascular cell adhesion molecule-1 (VCAM-1), a possible mediator of such remodeling. In the present study, we investigated whether this responsiveness persists at 12 months of age. Unlike 12month-old control mice, age-matched Snell dwarf mice remained resistant to training-induced maladaptive decreases in performance and muscle mass. This was accompanied by retainment of the remodeling capacity in muscles of Snell dwarf mice to increase VCAM-1 protein levels and a shift in myosin heavy chain (MHC) isoform distribution with training. Even decreasing training frequency for control mice, an alteration which protected muscles from maladaptation at $\mathbf{1 2}$ months of age, did not result in the overt remodeling observed for Snell dwarf mice. The results demonstrate a distinct remodeling response to resistance-type exercise operative in the context of the Pit1 ${ }^{d w / d w}$ mutation of long-lived Snell dwarf mice.
\end{abstract}

\section{INTRODUCTION}

The Snell dwarf mouse with a recessive mutation in Pit1 (Poulf1), an anterior pituitary transcriptional factor, results in combined anterior pituitary hormone deficiencies of growth hormone, thyrotropin, and prolactin has been an invaluable model to investigate lifespan extension [1]. The mouse model was first described almost a century ago and subsequently found to demonstrate compromised anterior pituitary development, muted development overall, and exceptional longevity $>40 \%$ relative to littermates [24]. Delayed or slowed aging in regards to $\mathrm{T}$ cell function, collagen cross-linking, incidence of cataracts, resistance to cancer, and kidney disease were observed to be concomitant with the lifespan extension $[2,5,6]$.

Previous research demonstrated that muscles of this longevity animal model are weak and demonstrate poor performance maintenance during activity at young age. Specifically, at 3 months of age for Snell dwarf mice, muscle quality (force normalized to muscle mass) was low and the capacity for isometric torque to be sustained in the minutes following contractions was especially compromised at values $20 \%$ of those for control littermates [7]. This outcome was not unexpected given the deficiency in growth hormone and, consequently, secondary deficiency in circulating 
insulin-like growth factor 1 (IGF-1)/insulin signaling [8-10]. Despite these deficiencies, however, muscles of young Snell dwarf mice responded to resistance-type training especially in terms of improvement in fatigue recovery capacity. Following the resistance-type exercise consisting of stretch-shortening contractions (SSCs), contractions consisting of a consecutive sequence of isometric, lengthening, and shortening contractions, 3 days per week for one month, muscles of Snell dwarf mice improved isometric torque following SSCs by $200 \%$ [7]. This was accompanied by muscle remodeling specific to Snell dwarf mice comprised of a shift in fiber type distribution to a slower phenotype. Furthermore, vascular cell adhesion molecule-1 (VCAM-1), a key mediator for the transmigration of monocyte and endothelial progenitor cells across the endothelium, was increased 4-fold [7, 11]. Such a response highlighted VCAM-1 as a candidate to consider as an intermediary for the fiber type remodeling which was observed. While this research provided insight in characterizing the responsiveness at young age in the presence of the Pit1 mutation, whether this remodeling signature persists was not tested.

The purpose of the present study was to characterize SSC training-induced performance changes, VCAM-1 upregulation, and muscle fiber type remodeling for Snell dwarf mice in the context of both 3- and 12months of age. The SSC protocol consisted of 80 maximally activated SSCs ( 8 sets of 10 repetitions) to the plantarflexor muscles of Snell dwarf mice and control littermates. Such a protocol was administered 3 days per week for one month and found to result in disparate outcomes depending on age and genotype. In supplemental testing regarding control mice, a decreased training frequency of 2 days per week was evaluated. Regardless of training exposure, muscles of control mice did not exhibit the overt alteration to myosin heavy chain (MHC) distribution and VCAM-1 protein levels observed for muscles of Snell dwarf mice. The results provide insight into the upregulation of VCAM-1 and shift in fiber type profile following resistance-type training as a potential compensatory mechanism in the context of pituitary hormone deficiency.

\section{RESULTS}

Frequent 3 day per week training initiated an agedependent decline in muscle mass, maximal performance, and muscle quality for control mice while no such training-induced decrement was observed for 12-month-old Snell dwarf mice

At young age, Snell dwarf body weights were $30 \%$ of those for control mice (Table 1). Tibial lengths of Snell dwarf mice were $70 \%$ of control values (Table 1 ). In the non-trained condition, Snell dwarf muscles were small, weak, and exhibited compromised torque maintenance following SSC session. Snell dwarf absolute mass and normalized mass (normalized to tibial length) values for the plantarflexor muscle group were $21 \%$ and $30 \%$ of control values, respectively (Table 1). Quantitative analysis of muscle fibers in transverse revealed that individual gastrocnemius muscle fibers of Snell dwarf mice were also smaller in cross-sectional area, $37 \%$ of control value (Supplementary Table 1). Muscle performance was affected by genotype to an even greater extent than that of muscle size. Maximal isometric torque, peak dynamic torque, and work outputs for non-trained Snell dwarf mice were only $12 \%$ to $15 \%$ of control values (Figure 1A and Supplementary Figure 1A, 1B, and 1C). Performance was low even after normalizing maximal isometric torque to muscle size to assess muscle quality, $43 \%$ of control values (Table 1). Isometric performance was also evaluated for the isometric portion of the final SSC of the training session and 5 minutes post session to assess torque depression at the termination of SSCs, torque recovery during the minutes following SSCs, and the torque depression that persisted 5 minutes post session (Figure $1 \mathrm{~B}, 1 \mathrm{C}$, and $1 \mathrm{D})$. Torque recovery in the minutes following the SSC session was compromised for muscles of Snell dwarf mice relative to control mice (Figure 1C). This low torque recovery for Snell dwarf mice was accompanied by a more pronounced extent of torque depression that persisted at 5 minutes post SSCs (Figure 1D).

The 3 days per week training at young age resulted in a ubiquitous reduction in isometric torque depression that persisted 5 minutes post SSCs especially for Snell dwarf mice. Training improved this measure by 1.5 -fold for control mice and 3.2-fold for Snell dwarf mice (Figure 1D). The reduction in torque depression for Snell dwarf mice was a result of diminished torque depression at the termination of the SSC session coupled with an unaltered torque recovery in the minutes following the session (Figure 1B and 1C). In contrast, the traininginduced decrease in torque depression at SSC session termination for control mice was coupled with a lower torque recovery (Figure $1 \mathrm{~B}$ and $1 \mathrm{C}$ ). Other measures including muscle size, maximal isometric torque, peak dynamic torque, stretch work, shorten work, and muscle quality were unaltered by the frequent training for both young control and Snell dwarf mice (Figure 1A, Table 1, and Supplementary Figure 1A, 1B, and 1C). Despite the absence of overall muscle mass changes for Snell dwarf mice, training induced an increase of 1.3-fold in total muscle fiber number density (Supplementary Table 2). This was suggestive of a decrease in muscle fiber size since percentage of tissue composed of interstitium 
Table 1. Body weight, tibial length, muscle mass, and muscle quality data for Snell dwarf and control mice following 3 days per week training.

\begin{tabular}{|c|c|c|c|c|c|c|c|c|c|c|c|}
\hline & \multirow[b]{2}{*}{$\begin{array}{c}\text { Body } \\
\text { weight }(g)\end{array}$} & \multirow[b]{2}{*}{$\begin{array}{c}\text { Tibial } \\
\text { length }(\mathrm{mm})\end{array}$} & \multicolumn{4}{|c|}{ Muscle mass (mg) } & \multicolumn{4}{|c|}{ Normalized muscle mass $(\mathrm{mg} / \mathrm{mm})$} & \multirow{2}{*}{$\begin{array}{l}\text { Muscle } \\
\text { quality } \\
(\mathrm{mN} \cdot \mathrm{m} / \\
\mathrm{mg} / \mathrm{mm})\end{array}$} \\
\hline & & & Gastrocnemius & Plantaris & Soleus & $\begin{array}{c}\text { Plantarflexor } \\
\text { group }\end{array}$ & Gastrocnemius & Plantaris & Soleus & $\begin{array}{c}\text { Plantarflexor } \\
\text { group }\end{array}$ & \\
\hline \multicolumn{12}{|l|}{ Control } \\
\hline \multicolumn{12}{|l|}{3 months old } \\
\hline Non-trained & $29.0 \pm 3.2$ & $18.5 \pm 0.3$ & $130.9 \pm 12.0$ & $16.7 \pm 3.3$ & $7.3 \pm 2.4$ & $154.9 \pm 16.0$ & $7.06 \pm 0.57$ & $0.90 \pm 0.17$ & $0.39 \pm 0.13$ & $8.36 \pm 0.79$ & $1.28 \pm 0.14$ \\
\hline \multicolumn{12}{|l|}{12 months old } \\
\hline Non-trained & $41.6 \pm 4.2^{\dagger}$ & $18.8 \pm 0.4$ & $123.9 \pm 12.9$ & $16.7 \pm 1.9$ & $8.5 \pm 0.9$ & $149.1 \pm 14.1$ & $6.57 \pm 0.60^{\dagger}$ & $0.88 \pm 0.10$ & $0.45 \pm 0.05$ & $7.91 \pm 0.65$ & $1.35 \pm 0.15$ \\
\hline 3 days/wk trained & $40.9 \pm 6.0^{\dagger}$ & $18.8 \pm 0.6^{\dagger}$ & $108.7 \pm 12.1^{* \dagger}$ & $15.1 \pm 2.5$ & $7.9 \pm 1.2$ & $131.7 \pm 13.8^{* \dagger}$ & $5.77 \pm 0.55^{* \dagger}$ & $0.80 \pm 0.12$ & $0.42 \pm 0.06$ & $6.99 \pm 0.60^{* \dagger}$ & $1.13 \pm 0.27^{*}$ \\
\hline \multicolumn{12}{|l|}{ Snell } \\
\hline \multicolumn{12}{|l|}{3 months old } \\
\hline Non-trained & $9.0 \pm 0.8^{\ddagger}$ & $13.2 \pm 0.5^{+}$ & $27.6 \pm 4.1^{\ddagger}$ & $3.5 \pm 1.1^{\ddagger}$ & $1.7 \pm 0.4$ & $32.8 \pm 5.1^{\ddagger}$ & $2.09 \pm 0.31^{\ddagger}$ & $0.26 \pm 0.09$ & $0.13 \pm 0.04$ & $2.49 \pm 0.39$ & $0.55 \pm 0.16^{\ddagger}$ \\
\hline \multicolumn{12}{|l|}{12 months old } \\
\hline Non-trained & $11.5 \pm 2.0^{\ddagger}$ & $13.0 \pm 0.5^{\ddagger}$ & $26.6 \pm 3.0^{\ddagger}$ & $4.0 \pm 0.9$ & $1.8 \pm 0.6^{\ddagger}$ & $32.4 \pm 2.9^{\ddagger}$ & $2.04 \pm 0.23^{\ddagger}$ & $0.31 \pm 0.06^{\ddagger}$ & $0.14 \pm 0.05^{\ddagger}$ & $2.49 \pm 0.22^{\ddagger}$ & $0.53 \pm 0.11^{\ddagger}$ \\
\hline 3 days/wk trained & $13.2 \pm 3.1^{\text {楼 }}$ & $13.2 \pm 0.4^{\ddagger}$ & $25.3 \pm 4.3^{\ddagger}$ & $3.3 \pm 0.8^{\ddagger}$ & $2.0 \pm 1.0^{\ddagger}$ & $30.6 \pm 4.3^{\ddagger}$ & $1.92 \pm 0.30^{\ddagger}$ & $0.25 \pm 0.06^{\ddagger}$ & $0.15 \pm 0.07^{\ddagger}$ & $2.32 \pm 0.31^{\ddagger}$ & $0.50 \pm 0.20^{\ddagger}$ \\
\hline
\end{tabular}

Values are expressed as means \pm SD. Sample sizes were $N=5$ to 10 per group. ${ }^{*}$ Different from comparable non-trained value. ${ }^{\dagger}$ Different from comparable 3 -month-old value. ${ }^{\ddagger}$ Different from comparable control value, $P<0.05$.

was unaltered with training $(19.0 \pm 1.9$ vs. $15.7 \pm 2.6 \%$ non-cellular interstitium; $5.9 \pm 0.8 \%$ vs. $5.4 \pm 2.1 \%$ cellular interstitium, $P>0.05$ ). When considering this along with the lack of change in absolute and normalized muscle mass, this suggested an increase in cross-sectional fiber number possibly due to hyperplasia or fiber splitting.

At 12 months of age, muscles of control mice maladapted to 3 days per week training while muscles of Snell dwarf mice remained resistant to such a response. For 12-month-old control mice, training induced a $12 \%$ reduction in absolute and normalized mass of the plantarflexor muscle group (Table 1). This age and genotype dependent response to training is indicated by an ANOVA interaction between genotype, age, and training $(P=0.0411)$ for normalized plantarflexor muscle mass. This reduction was due to mass loss primarily in the gastrocnemius muscle which also demonstrates an ANOVA interaction between genotype, age, and training $(P=0.0451)$ for normalized gastrocnemius muscle mass (Table 1). The muscle mass decreases coincided with a $18 \%$ smaller type IIb muscle fiber cross-sectional area with training (Supplementary Table 1). Isometric and dynamic performance measures were lowered by $20 \%$ to $25 \%$ with training (Figure $1 \mathrm{~A}$ and Supplementary Figure 1A, 1B, and 1C). While isometric torque depression at $\mathrm{SSC}$ session termination decreased with training, torque recovery in the minutes post SSCs was reduced and thereby resulted in a lack of training effect for torque depression persisting 5 minutes post SSCs (Figure 1B, 1C, and 1D). Furthermore, muscle quality values were $16 \%$ depressed compared with non-trained values (Table 1). The decrements in muscle mass and performance were not accompanied by alterations in percentage of tissue composed of non-degenerative muscle fibers (86.7 \pm $1.7 \%$ vs. $87.4 \pm 1.8 \%, P=0.847)$, degenerative muscle fibers $(0.3 \pm 0.1 \%$ vs. $0.0 \pm 0.0 \%, P=0.277)$, noncellular interstitium $(11.2 \pm 1.3 \%$ vs. $11.2 \pm 1.5 \%, P=$ $0.991)$, or cellular interstitium $(1.8 \pm 0.4 \%$ vs. $1.4 \pm$ $0.4 \%, P=0.736)$. An increase in percentage of tissue composed of central nucleated muscle fibers was observed, $24.9 \pm 7.0 \%$ vs. $9.6 \pm 4.9 \%, P=0.0172$. None of the training-induced alterations observed for the 12month-old control mice including performance decline were present for Snell dwarf mice (Figure 1 and Supplementary Figure 1).

Training-induced muscle remodeling in the form of alterations in fiber type distribution and VCAM-1 protein levels was especially prevalent for Snell dwarf mice across age groups

To further investigate the nature of tissue remodeling, fiber type and VCAM-1 distributions were evaluated. For Snell dwarf mice, the training response in torque depression reduction was accompanied by a shift in tissue composition away from type IIb muscle fibers to type IIx muscle fibers (Figures 2 and 3). The ability to shift fiber type distribution was preserved across age groups for Snell dwarf mice. Overall, these alterations in $\mathrm{MHC}$ isoform distribution were not accompanied by changes in cytochrome $\mathrm{c}$ oxidase $(\mathrm{COX}) /$ succinate dehydrogenase (SDH) histochemical double-labeling (Supplementary Figure 2 and Supplementary Table 3). 
Furthermore, for all the muscles analyzed, staining was dominated by light to dark brown COX label with no blue SDH staining evident. Such an outcome is consistent with normal COX activity (rather than defective COX synthesis or activity which allows for the blue reaction product of SDH to be apparent).

Immunofluorescence analysis was performed to determine the distribution of VCAM-1 in relation to capillaries as assessed by platelet endothelial cell adhesion molecule (CD31) localization (Supplementary Figure 3). ANOVA revealed that the main effects of age $(P=0.003)$ and genotype $(P=0.0008)$ impacted CD3 $1^{+}$ node density (Supplementary Table 4). Relative to non- trained muscles of 3-month-old control mice, muscles of comparable Snell dwarf mice displayed $48 \%$ greater total $\mathrm{CD} 31^{+}$nodes per $\mathrm{mm}^{2}$ tissue $(P=0.0315)$. The factor of age was apparent between trained muscles of the different age groups of Snell dwarf mice with $32 \%$ higher $\mathrm{CD} 31^{+}$node density at 12 months of age versus 3 months of age $(P=0.0413)$. A more pronounced distribution of VCAM-1 within capillaries was indicated in Snell dwarf mice by the finding of a significant ANOVA main effect of genotype $(P=$ 0.0273) regarding VCAM- $1^{+} / \mathrm{CD} 31^{+}$nodes $/ \mathrm{mm}^{2}$ (Supplementary Table 4). This was most apparent for muscles of trained 12-month-old Snell dwarf mice exhibiting a 3 -fold greater value of $\mathrm{VCAM}-1^{+} / \mathrm{CD} 31^{+}$

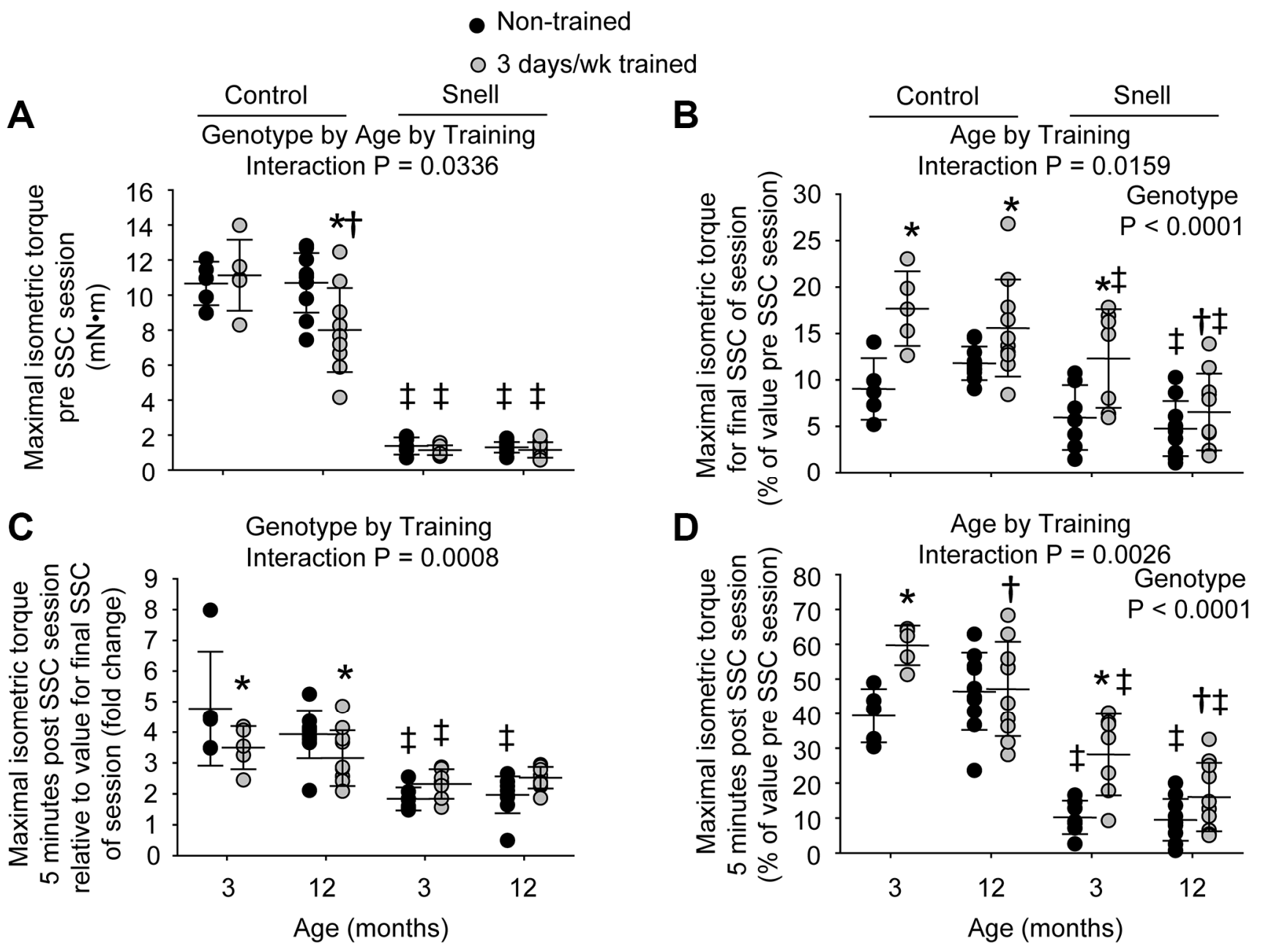

Figure 1. Muscles of Snell dwarf mice were resistant to age-dependent maladaptation from frequent SSC training. Training consisted of a frequency of 3 days per week for 1 month. (A) Maximal isometric torque output decreased with training for 12-month-old control mice while no such training-induced decrease was observed for Snell dwarf mice. (B) Torque depression by the final session SSC was generally reduced with training as assessed relative to pre SSC value. (C) Isometric torque recovery in the minutes following the SSC session was evaluated by comparing the 5 minute post SSC value with the final SSC value of the session. This recovery was unaltered with training for Snell dwarf mice unlike the reduced torque increase observed for control mice. (D) The overall isometric torque depression which persisted to 5 minutes post SSC session was reduced for 3-monthold mice with training regardless of genotype. Sample sizes were $N=5$ to 10 per group. Dots represent raw values. Lines denote means \pm SD. Relevant ANOVA interactions and main effects are noted. ${ }^{*}$ Different from non-trained value; ${ }^{\dagger}$ Different from comparable 3-month-old value, ${ }^{\ddagger}$ Different from comparable control value, $P<0.05$. 
nodes $/ \mathrm{mm}^{2}$ relative to values of age-matched trained control mice $(P=0.0117)$. No effect of training was observed for values of VCAM- $1^{+} / \mathrm{CD} 31^{+}$nodes $/ \mathrm{mm}^{2}$. Despite the lack of training effect on capillary localization of VCAM-1, protein levels of VCAM-1 were influenced by training (Figure 4). Traininginduced VCAM-1 protein levels were the most extreme for Snell dwarf mice as indicated by a genotype by training interaction $(P=0.017)$ and the observation of training values 2 -fold greater than those of control mice (Figure 4). Furthermore, traininginduced increases in VCAM-1 protein levels persisted at 12 months of age exclusively for Snell dwarf mice (Figure 4).
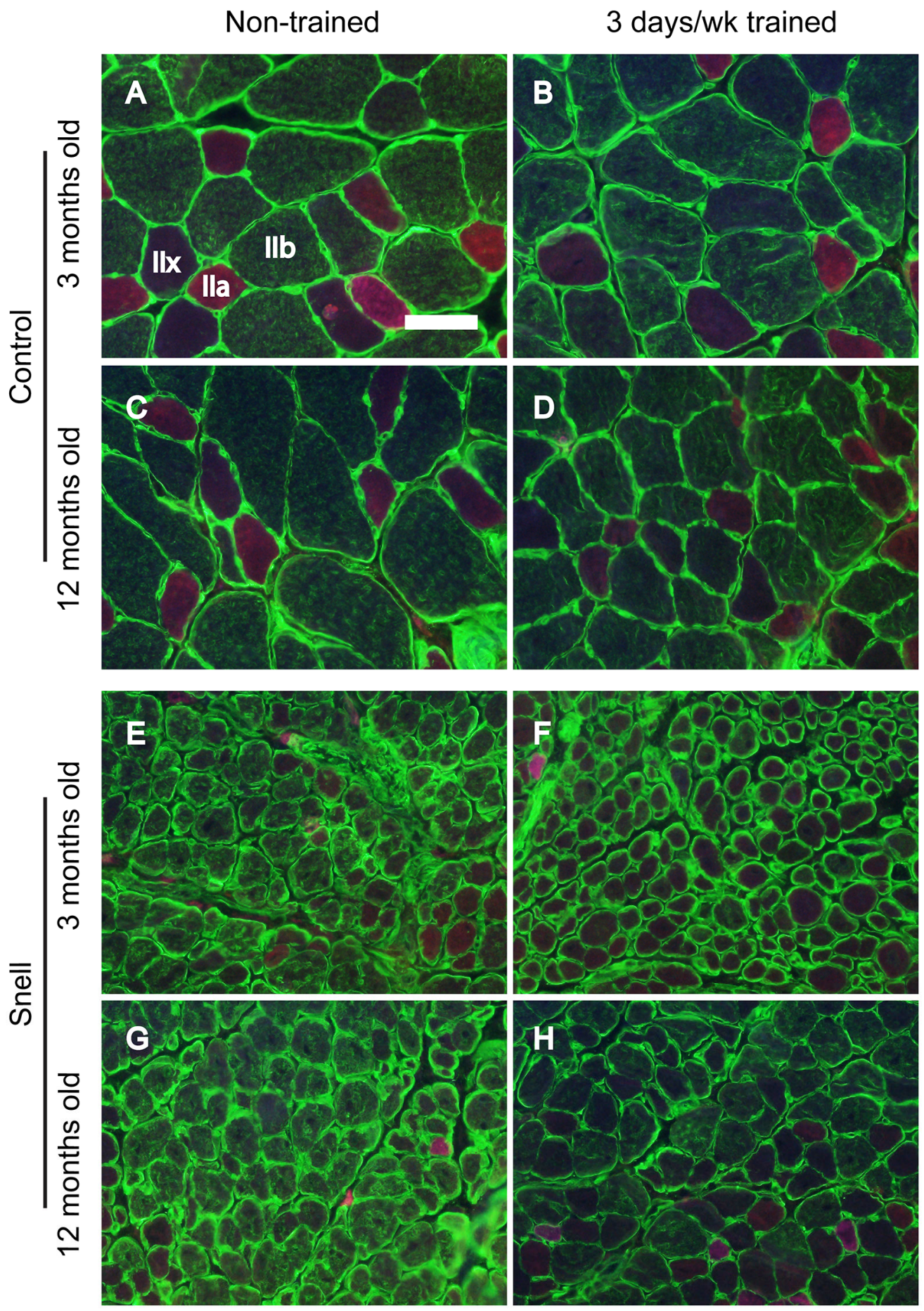

Figure 2. Fiber type immunofluorescence staining for muscles of control (A-D) and Snell dwarf (E-H) mice following 3 days per week training. Staining for laminin (green) and multiple MHC isoforms - IIb (green), Ila (red), and IIx (negative for staining) - are apparent in the images with shifting away from Ilb to Ilx with training unique to Snell dwarf mice. Scale bar $=50 \mu \mathrm{m}$. 
Less frequent 2 days per week training of control mice enhanced maximal performance for 3-monthold mice and induced no maladaptation for 12month-old mice - all in the absence of VCAM-1 and fiber type distribution alterations

To explore whether decreasing training frequency for control mice would allow time for greater overt muscle
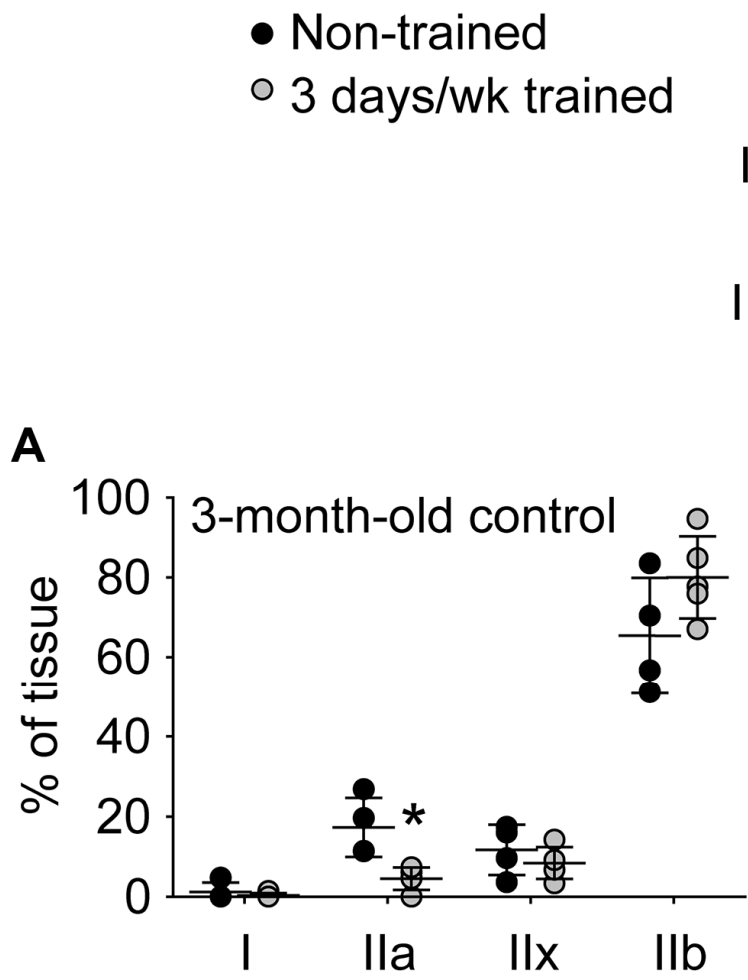

Fiber type

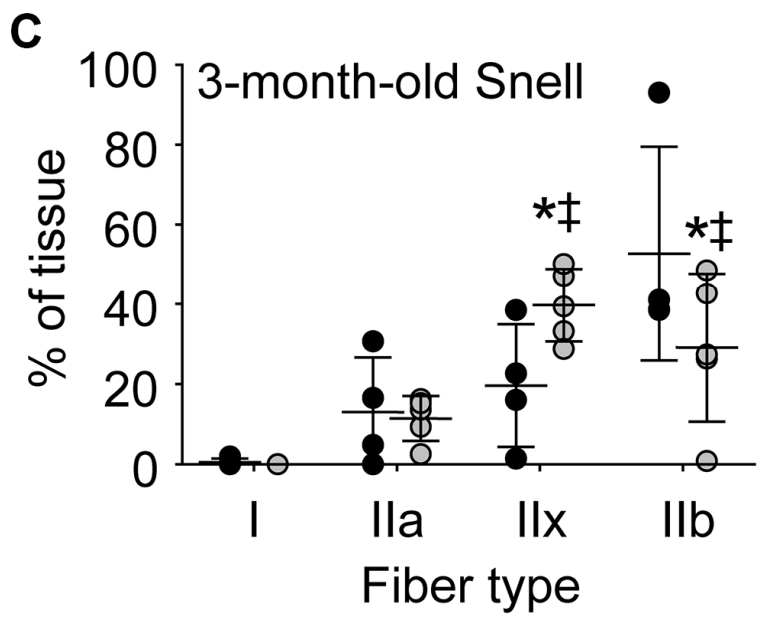

remodeling to occur, 2 days per week training was tested. At 3 months of age, absolute muscle masses and normalized muscle masses were unaltered by the training (Supplementary Table 5). Maximal isometric torque, peak dynamic torque, stretch work, and shorten work increased by a range of $22 \%$ to $27 \%$ with training (Supplementary Figures 4A and 5). Similarly, training increased muscle quality by $19 \%$ in an age dependent

Ila fiber type - age by training
interaction $P=0.0294$

Ilx fiber type - genotype by training
interaction $\mathrm{P}=0.0209$

Ilb fiber type - genotype by training interaction $\mathrm{P}=0.0099$

B


Figure 3. Fiber type analysis demonstrated a 3 days per week training-induced redistribution of tissue to a slower phenotype exclusively for 3-month-old and 12-month-old Snell dwarf mice. Percent of tissue composed of each fiber type for (A) 3-month-old control mice, (B) 12-month-old control mice, (C) 3-month-old Snell dwarf mice, (D) and 12-month-old Snell dwarf mice. Sample sizes were $N=4$ to 7 per group. Dots represent raw values. Lines denote means \pm SD. Relevant ANOVA interactions are noted. ${ }^{*}$ Different from comparable non-trained value, ${ }^{\ddagger}$ Different from comparable control value, $P<0.05$. No differences observed between age groups within genotype. 
manner for 3-month-old mice as indicated by an ANOVA interaction $(P=0.0221)$ between age and training (Supplementary Table 5). Unlike 3 day per week training, 2 day per week training did not induce any alterations in isometric torque depression or recovery for 3 month old mice (Supplementary Figure 4B, 4C, and 4D). While VCAM-1 protein levels were elevated to a moderate level (i.e. half of that for 3 days per week trained Snell dwarf mice) with training, no training-induced increase in $\mathrm{VCAM}-1^{+} / \mathrm{CD} 31^{+}$node density, $\mathrm{COX} / \mathrm{SDH}$ staining, or alteration in fiber type distribution was observed (Supplementary Figures 6-10 and Supplementary Tables 6-9).

For 12-month-old control mice, 2 day per week training did not induce maladaptation. Absolute muscle masses, normalized muscle masses, and muscle quality values were unchanged with training (Supplementary Table 5). Maximal isometric and dynamic performance remained unaltered upon training (Supplementary Figures 4A and 5). Regarding torque depression and recovery following an SSC session, training lowered the extent of torque recovery in the minutes following SSCs but this was not coupled with alterations in torque depression at the termination of the SSC session or at 5 minutes post SSCs (Supplementary Figure 4B, 4C, and 4D). These performance outcomes were accompanied by an increase in percentage of central nucleated muscle fibers with training $(18.3 \pm 5.6 \%$ vs. $7.0 \pm 2.7 \%, P=0.047)$ and no training-induced alterations $(P>0.05)$ in percentage of tissue composed of non-degenerative muscle fibers $(85.9 \pm 1.4 \%$ vs. $87.3 \pm 1.3 \%)$, degenerative muscle fibers $(0.1 \pm 0.1 \%$ vs. $0.0 \pm 0.0 \%)$, non-cellular interstitium $(12.1 \pm 1.0 \%$ vs. $11.7 \pm 1.2 \%)$, or cellular interstitium $(1.9 \pm 0.5 \%$ vs. $1.0 \pm 0.3 \%)$. No differences with training were observed in fiber type distribution, $\mathrm{COX} / \mathrm{SDH}$ staining, $\mathrm{VCAM}-1^{+} / \mathrm{CD} 31^{+}$ node density, or VCAM-1 protein levels (Supplementary Figures 6-10 and Supplementary Tables 6-9). Overall, these findings demonstrated that decreasing training frequency improved performance outcomes of maximal performance while not inducing the overt muscle remodeling observed for 3 days per week trained Snell dwarf mice. This highlights the uniqueness of the training-induced alterations in MHC isoform and VCAM-1 protein levels in Snell dwarf mice.

\section{DISCUSSION}

The present study demonstrates, in the context of Pit $1^{d w / d w}$ induced pituitary hormone deficiency, reduced maximal muscle performance coinciding with responsiveness to resistance-type SSC training and insusceptibility to training-induced maladaptation. This response in Snell dwarf mice was accompanied by remodeling in VCAM-1 protein levels and muscle fiber MHC isoform distribution thereby indicating these responses as possibly compensatory when anterior pituitary hormones are deficient. Overall, the results

- Non-trained

$\circ 3$ days/wk trained

Genotype by Training
Interaction $P=0.0170$

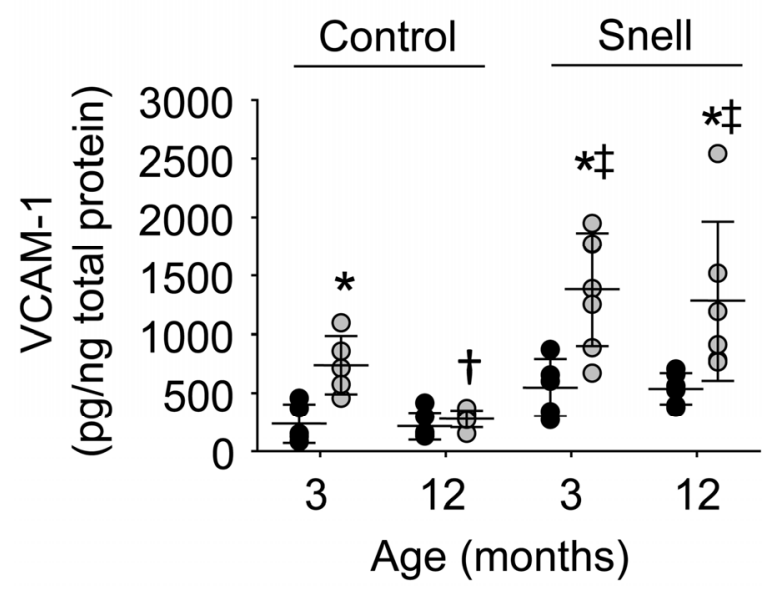

Figure 4. VCAM-1 protein levels within muscle homogenates following $\mathbf{3}$ days per week training. Exceptional VCAM-1 levels were reached in muscles of Snell dwarf mice upon training. Sample sizes were $N=5$ to 7 per group. Dots represent raw values. Lines denote means \pm SD. Relevant ANOVA interaction is noted. ${ }^{*}$ Different from comparable non-trained value, ${ }^{\dagger}$ Different from comparable 3-month-old value, ${ }^{\ddagger}$ Different from comparable control value, $P<0.05$. 
demonstrate for Snell dwarf mice that poor skeletal muscle performance can be addressed by SSC training and distinct remodeling without the typical extent of susceptibility to maladaptive overreaching/overtraining [12-18].

Based on associations observed between muscle quality and mortality as well as other age-dependent health outcomes, some have proposed that muscle quality is crucial for wellbeing throughout life [19-21]. Given this context, the finding of poor muscle quality and performance in general at baseline for the long-lived Snell dwarf mice even at young age in the present study could be considered unexpected. This finding may suggest that a lower threshold of muscle quality and performance is sufficient in laboratory conditions and/or that these muscle phenotypes are associative but not necessarily critical to longevity in some contexts. The study also furthers earlier work by demonstrating that diminished performance persists for Snell dwarf mice at 12 months of age thereby supporting the notion that this feature is long-term rather than transient [7]. Such an observation appears to be inherent in Snell dwarf mice due to disruption of growth hormone/insulin-like growth factor 1 (IGF-1)/insulin signaling [22]. This is not surprising since past studies reveal that both muscle strength and muscle quality (measures compromised for Snell dwarf mice in the present study) correlate with the growth hormone/IGF-1/insulin axis [8-10]. The present study is unique in demonstrating a long-term muscle performance deficit in the context of disrupted pituitary hormone/IGF-1/insulin signaling.

Despite poor baseline muscle performance, Snell dwarf mice demonstrated responsiveness to SSC training. Young Snell dwarf mice improved isometric torque and exhibited a 3.2-fold enhancement in the extent of isometric torque maintained 5 minutes post SSCs. This enhancement is meaningful even if poor muscle quality/performance can coexist with extended survival for Snell dwarf mice. While these muscle outcomes may be adequate in the laboratory setting such a phenotype maybe debilitating in a more natural setting. In this context, training-induced improvements in torque production and maintenance would be considered advantageous. This enhancement for Snell dwarf mice was accompanied by a shift from type IIb to IIx muscle fibers - an observation noted previously [7]. This shift in MHC isoform composition was not accompanied by an alteration in $\mathrm{COX} / \mathrm{SDH}$ staining. A disconnect between $\mathrm{MHC}$ isoform and oxidative enzyme capacity is not unprecedented [23-26]. Furthermore, studies regarding muscles of mice demonstrate that improvement in fatigue management can occur with a shift in MHC isoform distribution despite an absence of a change in oxidative enzyme activity [23, 24]. These findings are consistent with the observation that myofibrillar ATP utilization varies with $\mathrm{MHC}$ isoform content with type IIb fibers being energy inefficient, type IIx and IIa fibers being moderately energy efficient, and type I fibers being the most energy efficient [27, 28]. Therefore, the improvement in performance during training for the Snell dwarf mice may have been influenced by the shift in MHC isoform composition irrespective of the unaltered $\mathrm{COX} / \mathrm{SDH}$ profile. Concurrent with the shift in fiber type composition was an increase in VCAM-1 protein levels. VCAM-1 is a transmembrane adhesion protein of the immunoglobulin superfamily expressed on a wide range of cell types [29, 30]. In concert with selectins, VCAM1 mediates the transmigration of cells such as monocytes and endothelium progenitor cells to transverse the endothelium of blood vessels into peripheral tissue [11]. Such a role of VCAM-1 for ushering cells into muscle tissue has the potential to remodel the extracellular matrix, myonuclei population, and, consequently, muscle fiber type since distinct extracellular matrix properties/myonuclei populations associate with specific fiber types [31,32].

Even at 12 months of age in the present study, muscles of Snell dwarf mice retained remodeling capacity in terms of training-induced fiber type transformation and VCAM-1 protein upregulation. This was accompanied by the absence of maladaptation. This finding was not surprising given the slower fiber type profile at baseline for Snell dwarf mice (relative to control mice) and the further shift to even a slower fiber type distribution following training. Among different subtypes of type II fibers, slower fibers demonstrate less damage following eccentric contractions than faster fibers as illustrated by assessment of Z-band streaming in muscles of men following eccentric contractions [33]. This finding is also observed in muscles of rabbits [34]. Furthermore, investigation of individual muscle fibers isolated from men and women demonstrate that type II muscle fibers with different $\mathrm{MHC}$ isoform compositions also differ in susceptibility to contraction-induced force deficits (i.e. type II fibers with a slower MHC isoform composition exhibit lower force deficits relative to type II fibers with a faster MHC isoform distribution) [35]. Therefore, the initial high percentage of type IIx fibers in Snell dwarf muscles at baseline and the further shift of type IIb fibers to type IIx fibers upon training may decrease the propensity to accumulate myofibrillar damage and develop maladaptation.

An additional factor to consider when interpreting the differences observed between Snell dwarf mice and control mice in the present study is that Snell dwarf mice undergo delayed or impaired maturation (e.g., reproductive immaturity) $[5,36]$. Therefore, the Snell 
dwarf-specific results could have been due to processes associated with impaired maturation. Future work in which Snell dwarf are treated with hormonal supplementation for robust induction of puberty has the potential to address whether maturation state was a key factor in in regards to the outcomes of the present study [5]. Despite the various differences we observed between the Snell dwarf mice and control mice, they both shared the result of a muted improvement in post SSC isometric torque values at 12 months of age following 3 days per week training. This illustrates that although Snell dwarf mice appear to exhibit a betterpreserved phenotype across age groups in general (relative to the maladaptation observed for control mice), Snell dwarf mice do not escape the consequences of such age-dependent alterations entirely.

The maladaptive decrease in muscle mass and maximal isometric torque for 12-month-old control mice at adulthood following 3 days per week training in the present study demonstrated that an inappropriate resistance-type training protocol can become deleterious in a wild-type background early in life. This finding was consistent with a report regarding a similar protocol of 3 days per week SSC training for dorsiflexor muscles of rats [12]. While muscles of young 3-month old rats increased performance with training, muscles of adult 6month old rats decreased positive work capacity [12]. Careful modulation of frequency of high-intensity training has been demonstrated to be effective at improving resistance training outcomes at advancing age in human subjects [37]. Likewise in research utilizing 30-month-old rats, decreasing SSC training frequency from 3 to 2 days per week resulted in muscle mass and performance enhancement rather than decrement $[13,14]$. The present study confirms these findings thereby stressing the importance of recovery time by demonstrating no torque loss with training when 12-month-old control mice were exposed to 2 days per week training. Continued research regarding the modulation of training parameters for an expanded range of age groups is warranted to elucidate precise approaches to address distinct age-dependent muscular decrements.

\section{MATERIALS AND METHODS}

\section{Animals}

Male Snell dwarf (Pit $1^{d w / d w}$ ) mice and their agematched normal-sized control littermates were F1 generation produced by bidirectional mating of $\mathrm{DW} / \mathrm{J}$ Pit1 ${ }^{d w /+}$ (Jax\# 000643) and B6.DW Pit1 ${ }^{d w /+}$ (Jax\# 000772) mice. The investigators, equipment, and methods were the same as described in a previous report regarding SSC-trained plantarflexor muscles of young
(3 months old at training onset) Snell dwarf mice and their control littermates [7]. Furthermore, there was no appreciable gap in testing between age groups (i.e., testing of 12-month-old cohorts began within a month of completing testing of 3-month-old cohorts). Consequently, performance data and tissue obtained from trained muscles of these 3-month-old mice [7] were utilized for comparison purposes with those of mice at 12 months of age (at training onset) in the present study. Groups of heterozygote $\left(\right.$ Pit $1^{d w /+}$ ) and homozygote wild-type $\left(\mathrm{Pit}^{+/+}\right)$mice were pooled and categorized as control mice [38]. All the mice tested in this study were provided NIH-31 Open diet (Teklad 7917). The mice were housed in an AAALACaccredited animal quarters and at least one normal-sized female littermate was housed with Snell dwarf mice to provide warmth. Breeding and colony management of mice were done under specific-pathogen-free conditions with surveillance testing performed quarterly (test results were negative for pathogens). Mice were then transferred to a separate animal facility at least one week prior to SSC training and were housed in isolation in a dedicated rack of individually ventilated cages with HEPA filtration of supply air for the remainder of the study. All animal procedures were approved by the Centers for Disease Control and Prevention/National Institute for Occupational Safety and Health Morgantown Institutional Animal Care and Use Committee in Morgantown, WV.

\section{SSC training}

The SSC training protocol was based on a previous procedure demonstrated to induce muscle mass and performance gains in young rats [13, 14]. For each session, the mouse was anesthetized with isoflurane gas and placed in dorsal recumbency on a heated table. Plantarflexion muscle stimulation was performed via platinum electrodes placed subcutaneously to activate the tibial nerve and observed to induce plantarflexion. The left foot was then secured to a footplate of a dual mode muscle lever system (Whole Mouse Test System, 1300A, Aurora Scientific). Stimulation parameters were set for maximal contraction ( $8-\mathrm{V}$ magnitude, $0.2-\mathrm{ms}$ pulse duration, and $150-\mathrm{Hz}$ frequency). Isometric and dynamic performances were evaluated prior to the 80 SSC training. Isometric performance consisted of a single maximal isometric contraction with the ankle at $90^{\circ}$ (angle between tibia and foot). Dynamic performance was assessed by a single SSC test consisting of an isometric contraction for $200 \mathrm{~ms}$ at $110^{\circ}$ ankle angle followed by rotation to $70^{\circ}$ at $500^{\circ}$ per second, returning to $110^{\circ}$ at the same velocity, and holding at that angle for an additional $200 \mathrm{~ms}$ isometric contraction. For the single SSC test, peak torque and work values during the stretch and shorten phases of the 
SSC were determined. Work was determined by integrating the torque versus time curve and dividing by duration to calculate average torque and then multiplying by the angular displacement.

The training SSCs consisted of 8 sets (2-minute intervals between sets) with 10 SSCs per set (3-second intervals between SSCs) (Supplementary Figures 11 and 12). Muscles were maximally activated for each SSC at ankle angle $90^{\circ}$ for $100 \mathrm{~ms}$, rotated to $70^{\circ}$ at $60^{\circ} / \mathrm{s}$, returned to $90^{\circ}$ at $60^{\circ} / \mathrm{s}$, and deactivated $100 \mathrm{~ms}$ later. SSCs at a velocity of $60 \%$ induce a response characterized by the absence of overt muscle inflammation and degeneration in rodents days to weeks into training [7, 15, 39-41]. Isometric torque depression during and following the SSC session was assessed by comparing the torque for the isometric portion of the final SSC and the isometric torque 5 minutes following the SSCs, respectively, with pre SSCs maximal isometric torque. Torque recovery in the minutes following the SSC session was determined by dividing the isometric torque at 5 minutes post-SSCs by the value for the final SSC. Training consisted of one month of frequent 3 days per week training (Monday, Wednesday, and Friday) or less frequent 2 days per week training (Monday and Thursday) - two training schedules which resulted in distinct outcomes in previous research regarding old wild-type rats (i.e. 3 days per week training was maladaptive while 2 days per week training was adaptive) $[13,14]$. Non-trained values for maximal performance measures and muscle tissue analyses were from mice exposed to the same procedures (e.g., time-matched anesthetization and assessment of maximal performance) and weekly schedule as trained mice with the exception that no training SSCs were administered. Initial and final performance values were determined by averaging the first and last week, respectively. Plantarflexor muscles were removed and weighed 72 hours after the final exposure. Tibia length was also measured and used to determine normalized muscle mass (muscle mass divided by tibia length). Muscle quality was calculated by dividing maximal isometric torque by normalized muscle mass of the plantarflexor muscle group. Each gastrocnemius muscle mid-belly portion was immersed in tissue freezing media and placed in cold isopentane $\left(-160^{\circ} \mathrm{C}\right)$ for quantitative morphology/immunofluorescence while remaining tissue was stored for ELISA.

\section{Quantitative morphology}

Gastrocnemius muscle tissue was cryosectioned at 12 $\mu \mathrm{m}$ thickness, stained with hematoxylin and eosin, and analyzed by a standardized stereological procedure [7, 14, 41, 42]. The investigator was blinded to sample identification. At 40X magnification, 5 fields (or maximum number of fields possible without overlap) were evaluated both right and left of the midline of the muscle section so that up to a total of 10 fields were assessed per muscle section. At each field, points of a 121-point 11-line overlay graticule $\left(0.04 \mathrm{~mm}^{2}\right.$ square with 100 divisions) were evaluated with each point identified as overlaying a muscle fiber (degenerative or non-degenerative) or interstitium (cellular or noncellular). Degenerative muscle fibers were characterized as loss of contact with surrounding fibers, interdigitation of the sarcolemma by cellular infiltrates, and internalization of cellular infiltrates [42]. A point was categorized as overlying cellular interstitium when the point was over a nucleus in-between muscle fibers. A point overlaying a region lacking nuclei outside muscle fibers was characterized as cellular interstitium. Percent of muscle tissue comprised of non-degenerative muscle fibers, degenerative muscle fibers, centrally nucleated muscle fibers, cellular interstitium, or noncellular interstitium were calculated as the percentage of points which overlaid each type of tissue relative to the total number of points. Number of muscle fibers per unit cross-sectional area was determined by counting the number of muscle fibers in which the topmost part of the fiber was within the graticule boundary. Mean muscle fiber area $\left(\mu \mathrm{m}^{2}\right)$ was determined by dividing the percent of tissue comprised of muscle fibers by fiber number per unit area.

\section{Immunofluorescence}

Gastrocnemius muscle transverse sections were stained for MHC isoforms using a previously described method [7, 41]. Sections were blocked (10\% goat serum in PBS for 1 hour at room temperature) and incubated in a primary antibody cocktail overnight at $4{ }^{\circ} \mathrm{C}$ - antibodies against MHC I (BA-F8; 1:10), MHC IIa (SC-71; 1:200), MHC IIb (BF-F3;1:200), and laminin (L9393;1:400). Sections were then exposed to secondary antibodies (Alexa Fluor from Life Technologies) for 2 hours at room temperature - 350 IgG2b goat anti mouse (A21140; 1:250), 594 IgG1 goat anti-mouse (A21125; 1:100), 488 IgM goat anti-mouse (A21042; 1:500), and 488 IgG goat anti-rabbit (A11008; 1:500). Analysis of Fiber type distribution was performed by a standardized stereological method with investigator blinded to sample identification [7, 41]. At both lateral and medial regions of the muscle section, non-overlapping images were captured and an overlay graticule (with 0.04 $\mathrm{mm}^{2}$ square boundary) was placed at the center of each image. Each point of intersection was categorized as overlaying MHC I (blue), MHC IIa (red), MHC IIb (green), MHC IIx (lacking staining), or interstitium. Percent of muscle tissue comprised of each fiber type was calculated as the percentage of points which overlaid each type of tissue relative to the total number of points. Number of muscle fibers of each type in which the 
topmost portion was within the boundary of the graticule were also counted. Total number of fibers counted divided by the total area sampled was calculated to determine the number of fibers per unit cross-sectional area. Mean muscle fiber area $\left(\mu \mathrm{m}^{2}\right)$ was determined by dividing the percent of tissue comprised of a particular fiber type by the appropriate fiber number per unit area.

For analysis of VCAM-1 distribution, gastrocnemius muscle sections were fixed in HistoChoice (SigmaAldrich; H2904) for 45 minutes at room temperature, washed with phosphate-buffered saline (PBS, $3 \times 5$ minutes), and permeabilized in $0.2 \%$ Tween 20 for 10 minutes. Sections were blocked for 1 hour (10\% donkey serum in PBST at room temperature) and incubated overnight $\left(4^{\circ} \mathrm{C}\right)$ with primary antibodies against VCAM-1 (PA5-47029 at 1:200 in blocking solution, ThermoFisher Scientific), laminin (L9393 at 1:400 in blocking solution, Sigma-Aldrich), and CD31 (550274, a marker of endothelial cells of blood vessels, at 1:50 in blocking solution, BD Pharmingen). This was followed by a 1 hour incubation with secondary antibodies (A11058 donkey anti-goat IgG Alexa Fluor 594, ThermoFisher Scientific, A21208 donkey anti-rabbit IgG Alexa Fluor 488, and A10039 donkey anti-rabbit IgG, ThermoFisher Scientific; each at 1:500 in PBST). The sections were mounted with a coverslip using Prolong Gold antifade mountant (P10144, ThermoFisher Scientific). With the investigator blinded to section identification, midpoint of the muscle section was identified and non-overlapping images were captured at the lateral and medial regions of the muscle section. An overlay graticule (with $0.04 \mathrm{~mm}^{2}$ square boundary) was placed at the center of each image and the investigator counted total number of $\mathrm{CD} 31^{+}$nodes (anatomical features encircled by laminin, adjacent to muscle fibers, and positive for CD31 staining thereby indicative of capillaries) and the subset of $\mathrm{CD} 31^{+}$nodes that were also positive for VCAM-1 staining (i.e. number of $\mathrm{CD} 31^{+} \mathrm{VCAM}-1^{+}$nodes) provided the topmost region of each node resided within the graticule boundary. Number of nodes were normalized by total muscle section area sampled.

\section{Histochemistry}

Transverse cryostat sections $(12 \mu \mathrm{m})$ of gastrocnemius muscle were exposed to a modified version of a standard COX/SDH double-labeling assay [43]. Sections were incubated with COX reaction mixture (1.4 $\mathrm{mM}$ diaminobenzidine tetrahydrochloride, $22 \mu \mathrm{M}$ sucrose, $41 \mu \mathrm{M}$ cytochrome $c$, and $20 \mu \mathrm{g} / \mathrm{ml}$ catalase in PBS, $\mathrm{pH}$ 7.6) for 1 hour at $37^{\circ} \mathrm{C}$. The sections were rinsed with distilled water then then incubated with SDH reaction mixture $(93 \mathrm{mM}$ sodium succinate and $1.5 \mathrm{mM}$ nitroblue tetrazolium in PBS, $\mathrm{pH}$ 7.6) for 1 hour at $37^{\circ} \mathrm{C}$. With the investigator blinded to section identification, midpoint of the muscle section was identified. At 40X magnification, 5 fields (or maximum number of fields possible without overlap) were evaluated both right and left of the midline of the muscle section so that up to a total of 10 fields were assessed per muscle section. An overlay graticule (with $0.04 \mathrm{~mm}^{2}$ square boundary) was placed at the center of each field and the investigator visually classified each muscle fiber within the graticule boundary.

\section{ELISA}

Gastrocnemius muscle tissue was homogenized in PBS (25 $\mu \mathrm{l}$ per $\mathrm{mg}$ of tissue) containing Halt Protease Inhibitor Cocktail (Thermo Scientific, 78438), centrifuged at $1500 \mathrm{rcf}$ for 15 minutes at $4^{\circ} \mathrm{C}$, and supernatant collected for ELISA analysis for VCAM-1 (Quanterix Custom Array Kit, \#100-0286) per standard kit instructions. Aushon Cirascan Imaging System was used to obtain images of the arrays. Total protein was determined using a standard colorimetric bicinchoninic acid (BCA) protein assay (Pierce, Rockford, IL, USA).

\section{Statistical analysis}

Data were analyzed using ANOVA (JMP version 11, SAS Institute, Inc., Cary, NC, USA) with the variable of animal identification as a random factor to account for repeated measures when appropriate. Post hoc comparisons were performed using Fisher's least significant difference method. Data regarding type I fiber results were not normally distributed and, therefore, analyzed by Kruskal Wallis ANOVA on ranks. All data are expressed as means \pm standard deviation (SD). $P<0.05$ was considered statistically significant.

\section{AUTHOR CONTRIBUTIONS}

E.P.R. and B.A.B. designed the study, interpreted the data, and wrote the manuscript; E.P.R., M.A.N., J.E. and B.A.B. performed the experiments. All authors approved the final version of the manuscript.

\section{ACKNOWLEDGMENTS}

The findings and conclusions in this report are those of the author(s) and do not necessarily represent the official position of the National Institute for Occupational Safety and Health, Centers for Disease Control and Prevention.

\section{CONFLICTS OF INTEREST}

The authors declare no conflicts of interest related to this study. 


\section{FUNDING}

This study was supported by internal National Institute for Occupational Safety and Health funds. The funding body did not have a role in the design of the study, collection, analysis, interpretation of data, and writing of the manuscript.

\section{REFERENCES}

1. Bartke A, Darcy J. GH and ageing: Pitfalls and new insights. Best Pract Res Clin Endocrinol Metab. 2017; 31:113-25.

https://doi.org/10.1016/i.beem.2017.02.005 PMID:28477727

2. Flurkey K, Papaconstantinou J, Miller RA, Harrison DE. Lifespan extension and delayed immune and collagen aging in mutant mice with defects in growth hormone production. Proc Natl Acad Sci U S A. 2001; 98:6736-41. https://doi.org/10.1073/pnas.111158898 PMID:11371619

3. Flurkey K, Papaconstantinou J, Harrison DE. The Snell dwarf mutation Pit1(dw) can increase life span in mice. Mech Ageing Dev. 2002; 123:121-30. https://doi.org/10.1016/s0047-6374(01)00339-6 PMID: 11718806

4. Snell GD. DWARF, A new mendelian recessive character of the house mouse. Proc Natl Acad Sci U S A. $1929 ; 15: 733-4$. https://doi.org/10.1073/pnas.15.9.733 PMID:16577229

5. Vergara $M$, Smith-Wheelock $M$, Harper JM, Sigler R, Miller RA. Hormone-treated snell dwarf mice regain fertility but remain long lived and disease resistant. J Gerontol A Biol Sci Med Sci. 2004; 59:1244-50. https://doi.org/10.1093/gerona/59.12.1244 PMID:15699523

6. Alderman JM, Flurkey K, Brooks NL, Naik SB, Gutierrez $J M$, Srinivas $U$, Ziara KB, Jing L, Boysen G, Bronson R, Klebanov S, Chen X, Swenberg JA, et al. Neuroendocrine inhibition of glucose production and resistance to cancer in dwarf mice. Exp Gerontol. 2009; 44:26-33.

https://doi.org/10.1016/j.exger.2008.05.014 PMID: 18582556

7. Rader EP, Naimo MA, Ensey J, Baker BA. VCAM-1 upregulation accompanies muscle remodeling following resistance-type exercise in Snell dwarf (Pit1 ${ }^{\mathrm{dw} / \mathrm{dw}}$ ) mice. Aging Cell. 2018; 17:e12816.

https://doi.org/10.1111/acel.12816

PMID:29992743

8. Huuskonen A, Lappalainen J, Oksala N, Santtila M, Häkkinen K, Kyröläinen H, Atalay M. Common genetic variation in the IGF1 associates with maximal force output. Med Sci Sports Exerc. 2011; 43:2368-74. https://doi.org/10.1249/MSS.0b013e3182220179 PMID:21552154

9. Cuneo RC, Salomon F, Wiles CM, Sönksen PH. Skeletal muscle performance in adults with growth hormone deficiency. Horm Res. 1990 (Suppl 4); 33:55-60. https://doi.org/10.1159/000181585 PMID:2245969

10. Cuneo RC, Wallace JD. Skeletal and cardiac muscle in adults with growth hormone deficiency. Front Horm Res. 2005; 33:121-45. https://doi.org/10.1159/000088420 PMID:16166759

11. Strömberg A, Rullman E, Jansson E, Gustafsson T. Exercise-induced upregulation of endothelial adhesion molecules in human skeletal muscle and number of circulating cells with remodeling properties. J Appl Physiol (1985). 2017; 122:1145-54. https://doi.org/10.1152/japplphysiol.00956.2016 PMID:28183821

12. Rader EP, Layner K, Triscuit AM, Chetlin RD, Ensey J, Baker BA. Age-dependent Muscle Adaptation after Chronic Stretch-shortening Contractions in Rats. Aging Dis. 2016; 7:1-13. https://doi.org/10.14336/AD.2015.0920 PMID:26816659

13. Naimo MA, Rader EP, Ensey J, Kashon ML, Baker BA. Reduced frequency of resistance-type exercise training promotes adaptation of the aged skeletal muscle microenvironment. J Appl Physiol (1985). 2019; 126:1074-87.

https://doi.org/10.1152/japplphysiol.00582.2018 PMID:30676867

14. Rader EP, Naimo MA, Layner KN, Triscuit AM, Chetlin RD, Ensey J, Baker BA. Enhancement of Skeletal Muscle in Aged Rats Following High-Intensity StretchShortening Contraction Training. Rejuvenation Res. 2017; 20:93-102. https://doi.org/10.1089/rej.2016.1816 PMID:27378453

15. Cutlip RG, Baker BA, Geronilla KB, Mercer RR, Kashon ML, Miller GR, Murlasits Z, Alway SE. Chronic exposure to stretch-shortening contractions results in skeletal muscle adaptation in young rats and maladaptation in old rats. Appl Physiol Nutr Metab. 2006; 31:573-87. https://doi.org/10.1139/h06-033 PMID:17111012

16. Fry AC, Kraemer WJ, van Borselen F, Lynch JM, Marsit JL, Roy EP, Triplett NT, Knuttgen HG. Performance decrements with high-intensity resistance exercise 
overtraining. Med Sci Sports Exerc. 1994; 26:1165-73. PMID:

17. Barbe MF, Gallagher S, Massicotte VS, Tytell M, Popoff SN, Barr-Gillespie AE. The interaction of force and repetition on musculoskeletal and neural tissue responses and sensorimotor behavior in a rat model of work-related musculoskeletal disorders. BMC Musculoskelet Disord. 2013; 14:303. https://doi.org/10.1186/1471-2474-14-303 PMID:24156755

18. Massicotte VS, Frara N, Harris MY, Amin M, Wade CK, Popoff SN, Barbe MF. Prolonged performance of a high repetition low force task induces bone adaptation in young adult rats, but loss in mature rats. Exp Gerontol. 2015; 72:204-17.

https://doi.org/10.1016/i.exger.2015.10.014 PMID:26517953

19. Sui SX, Williams LJ, Holloway-Kew KL, Hyde NK, Leach $\mathrm{S}$, Pasco JA. Associations Between Muscle Quality and Cognitive Function in Older Men: Cross-Sectional Data From the Geelong Osteoporosis Study. J Clin Densitom. 2021. [Epub ahead of print]. https://doi.org/10.1016/j.jocd.2021.03.007 PMID:33879389

20. Brown JC, Harhay MO, Harhay MN. The muscle quality index and mortality among males and females. Ann Epidemiol. 2016; 26:648-53. https://doi.org/10.1016/j.annepidem.2016.07.006 PMID:27480478

21. Larsen B, Bellettiere J, Allison M, McClelland RL, Miljkovic I, Vella CA, Ouyang P, De-Guzman KR, Criqui $\mathrm{M}$, Unkart J. Muscle area and density and risk of allcause mortality: The Multi-Ethnic Study of Atherosclerosis. Metabolism. 2020; 111:154321. https://doi.org/10.1016/j.metabol.2020.154321 PMID: $\underline{32712219}$

22. Bartke A, Sun LY, Longo V. Somatotropic signaling: tradeoffs between growth, reproductive development, and longevity. Physiol Rev. 2013; 93:571-98. https://doi.org/10.1152/physrev.00006.2012 PMID:23589828

23. Hendrickse PW, Krusnauskas R, Hodson-Tole E, Venckunas $T$, Degens $H$. Endurance exercise plus overload induces fatigue resistance and similar hypertrophy in mice irrespective of muscle mass. Exp Physiol. 2020; 105:2110-22. https://doi.org/10.1113/EP089096 PMID:33140456

24. Ballak SB, Busé-Pot $T$, Harding PJ, Yap MH, Deldicque $L$, de Haan A, Jaspers RT, Degens $H$. Blunted angiogenesis and hypertrophy are associated with increased fatigue resistance and unchanged aerobic capacity in old overloaded mouse muscle. Age (Dordr). 2016; 38:39.

https://doi.org/10.1007/s11357-016-9894-1

PMID:26970774

25. Otis JS, Roy RR, Edgerton VR, Talmadge RJ. Adaptations in metabolic capacity of rat soleus after paralysis. J Appl Physiol (1985). 2004; 96:584-96. https://doi.org/10.1152/japplphysiol.00724.2003 PMID:14565962

26. Pellegrino MA, D'Antona $G$, Bortolotto $S$, Boschi $F$, Pastoris O, Bottinelli R, Polla B, Reggiani C. Clenbuterol antagonizes glucocorticoid-induced atrophy and fibre type transformation in mice. Exp Physiol. 2004; 89:89-100.

https://doi.org/10.1113/expphysiol.2003.002609 PMID:15109214

27. Stienen GJ, Kiers JL, Bottinelli R, Reggiani C. Myofibrillar ATPase activity in skinned human skeletal muscle fibres: fibre type and temperature dependence. J Physiol. 1996; 493:299-307. https://doi.org/10.1113/jphysiol.1996.sp021384 PMID:8782097

28. Bottinelli R, Canepari M, Reggiani C, Stienen GJ. Myofibrillar ATPase activity during isometric contraction and isomyosin composition in rat single skinned muscle fibres. J Physiol. 1994; 481:663-75. https://doi.org/10.1113/iphysiol.1994.sp020472

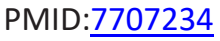

29. Choo HJ, Canner JP, Vest KE, Thompson Z, Pavlath GK. A tale of two niches: differential functions for VCAM1 in satellite cells under basal and injured conditions. Am J Physiol Cell Physiol. 2017; 313:C392-404. https://doi.org/10.1152/ajpcell.00119.2017 PMID:28701357

30. Li D, Xue W, Li M, Dong M, Wang J, Wang X, Li X, Chen K, Zhang W, Wu S, Zhang Y, Gao L, Chen $Y$, et al. VCAM $-1^{+}$macrophages guide the homing of HSPCs to a vascular niche. Nature. 2018; 564:119-24. https://doi.org/10.1038/s41586-018-0709-7 PMID:30455424

31. Wood LK, Kayupov E, Gumucio JP, Mendias CL, Claflin DR, Brooks SV. Intrinsic stiffness of extracellular matrix increases with age in skeletal muscles of mice. J Appl Physiol (1985). 2014; 117:363-9. https://doi.org/10.1152/japplphysiol.00256.2014 PMID:24994884

32. Martins KJ, Murdoch GK, Shu Y, Harris RL, Gallo M, Dixon WT, Foxcroft GR, Gordon T, Putman CT. Satellite cell ablation attenuates short-term fast-toslow fibre type transformations in rat fast-twitch skeletal muscle. Pflugers Arch. 2009; 458:325-35. https://doi.org/10.1007/s00424-008-0625-z PMID:19130076 
33. Fridén J, Sjöström M, Ekblom B. Myofibrillar damage following intense eccentric exercise in man. Int J Sports Med. 1983; 4:170-6.

https://doi.org/10.1055/s-2008-1026030

PMID: 6629599

34. Lieber RL, Woodburn TM, Fridén J. Muscle damage induced by eccentric contractions of $25 \%$ strain. J Appl Physiol (1985). 1991; 70:2498-507. https://doi.org/10.1152/jappl.1991.70.6.2498 PMID: 1885443

35. Choi SJ, Widrick JJ. Calcium-activated force of human muscle fibers following a standardized eccentric contraction. Am J Physiol Cell Physiol. 2010; 299:C1409-17.

https://doi.org/10.1152/ajpcell.00226.2010 PMID:20810908

36. Bartke A, Coschigano K, Kopchick J, Chandrashekar V, Mattison J, Kinney B, Hauck S. Genes that prolong life: relationships of growth hormone and growth to aging and life span. J Gerontol A Biol Sci Med Sci. 2001; 56:B340-9.

https://doi.org/10.1093/gerona/56.8.b340 PMID:11487592

37. Stec MJ, Thalacker-Mercer A, Mayhew DL, Kelly NA, Tuggle SC, Merritt EK, Brown CJ, Windham ST, Dell'Italia LJ, Bickel CS, Roberts BM, Vaughn KM, Isakova-Donahue I, et al. Randomized, four-arm, dose-response clinical trial to optimize resistance exercise training for older adults with age-related muscle atrophy. Exp Gerontol. 2017; 99:98-109. https://doi.org/10.1016/j.exger.2017.09.018 PMID:28964826

38. Madsen MA, Hsieh CC, Boylston WH, Flurkey $K$, Harrison D, Papaconstantinou J. Altered oxidative stress response of the long-lived Snell dwarf mouse. Biochem Biophys Res Commun. 2004; 318:998-1005. https://doi.org/10.1016/j.bbrc.2004.04.126 PMID:15147972
39. Baker BA, Hollander MS, Mercer RR, Kashon ML, Cutlip RG. Adaptive stretch-shortening contractions: diminished regenerative capacity with aging. Appl Physiol Nutr Metab. 2008; 33:1181-91.

https://doi.org/10.1139/H08-110

PMID:19088776

40. Baker BA, Hollander MS, Kashon ML, Cutlip RG. Effects of glutathione depletion and age on skeletal muscle performance and morphology following chronic stretch-shortening contraction exposure. Eur J Appl Physiol. 2010; 108:619-30. https://doi.org/10.1007/s00421-009-1258-4 PMID:19882165

41. Rader EP, Naimo MA, Ensey J, Baker BA. Agonist muscle adaptation accompanied by antagonist muscle atrophy in the hindlimb of mice following stretch-shortening contraction training. BMC Musculoskelet Disord. 2017; 18:60. https://doi.org/10.1186/s12891-017-1397-4 PMID:28148306

42. Baker BA, Mercer RR, Geronilla KB, Kashon ML, Miller GR, Cutlip RG. Stereological analysis of muscle morphology following exposure to repetitive stretchshortening cycles in a rat model. Appl Physiol Nutr Metab. 2006; 31:167-79.

https://doi.org/10.1139/h05-009

PMID:16604135

43. Ross JM. Visualization of mitochondrial respiratory function using cytochrome c oxidase/succinate dehydrogenase (COX/SDH) double-labeling histochemistry. J Vis Exp. 2011; 57:e3266.

https://doi.org/10.3791/3266

PMID:22143245 


\section{SUPPLEMENTARY MATERIALS}

\section{Supplementary Figures}

- Non-trained

O 3 days/wk trained
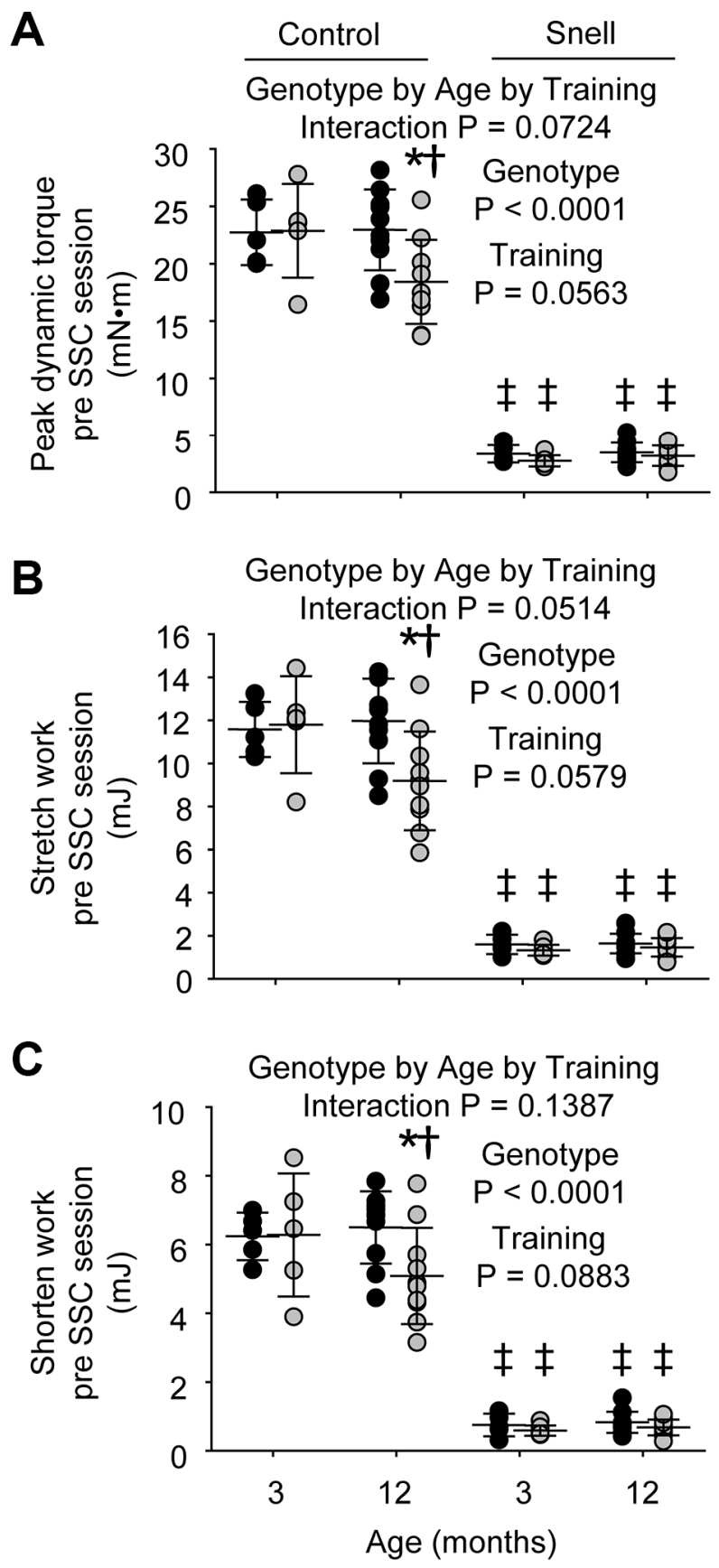

Supplementary Figure 1. Dynamic performance for non-trained and trained muscles of control and Snell dwarf mice. The dynamic measures of (A) peak dynamic torque, (B) stretch work, and (C) shorten work decreased with training for 12-month-old control mice while no such training-induced decrease was present for Snell dwarf mice. Sample sizes were $N=5$ to 10 per group. Dots represent raw values. Lines denote means \pm SD. Relevant ANOVA interactions and main effects are noted. "Different from non-trained value; ${ }^{+}$Different from comparable 3-month-old value, ${ }^{\ddagger}$ Different from comparable control value, $p<0.05$. 

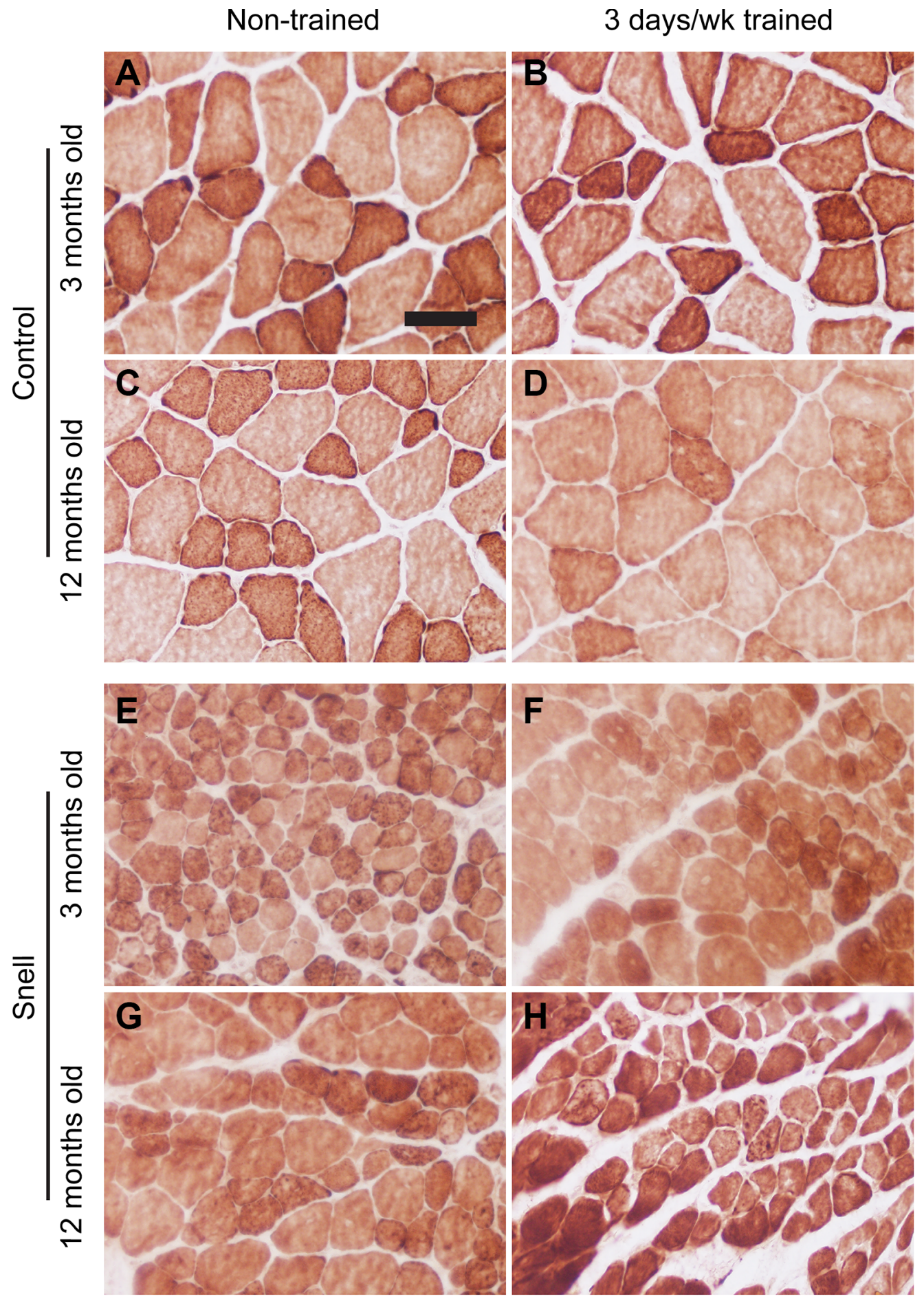

Supplementary Figure 2. $\mathrm{COX} / \mathrm{SOH}$ labeling of muscles of mice following 3 days per week training. Images depict muscles of control (A-D) and Snell dwarf (E-H) mice. COX positive muscle fibers dominated displaying light and dark brown staining. No blue (COX deficient $/$ SDH positive) fibers were observed. Scale bar $=50 \mu \mathrm{m}$. 

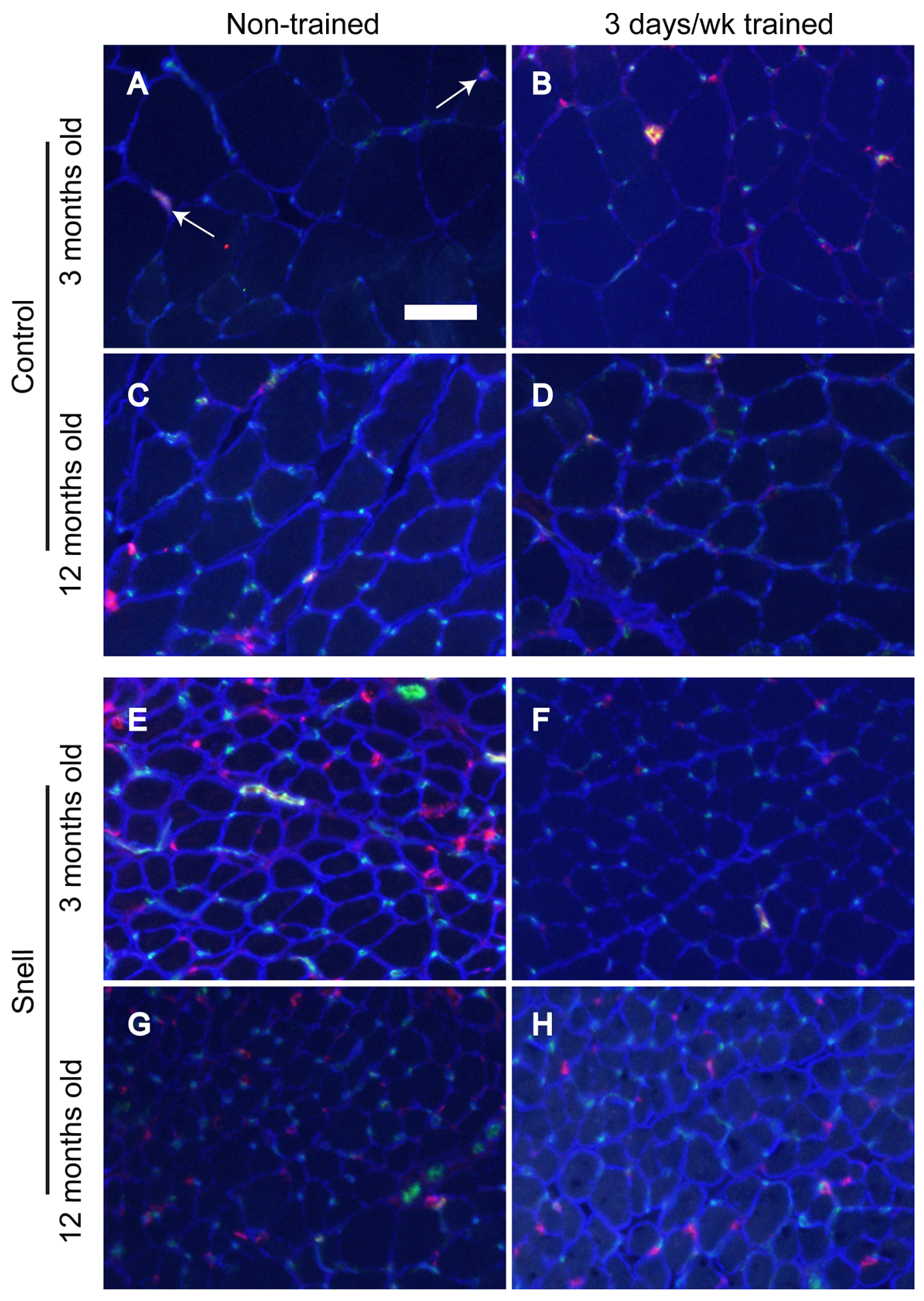

Supplementary Figure 3. Immunofluorescence staining for laminin (blue), CD31 (green), and VCAM-1 (red) in muscles of mice following 3 days per week training. Nodes (laminin encircled features adjacent to muscle fibers) were assessed for $\mathrm{CD} 31^{+}$and VCAM- $1^{+} / \mathrm{CD} 31^{+}$labeling (arrows depict VCAM-1 $1^{+} / \mathrm{CD} 31^{+}$examples in panel A) as an indicator of distribution of VCAM-1 within capillaries. Images were taken from muscles of control (A-D) and Snell dwarf $(\mathbf{E}-\mathbf{H})$ mice. Scale bar $=50 \mu \mathrm{m}$. 


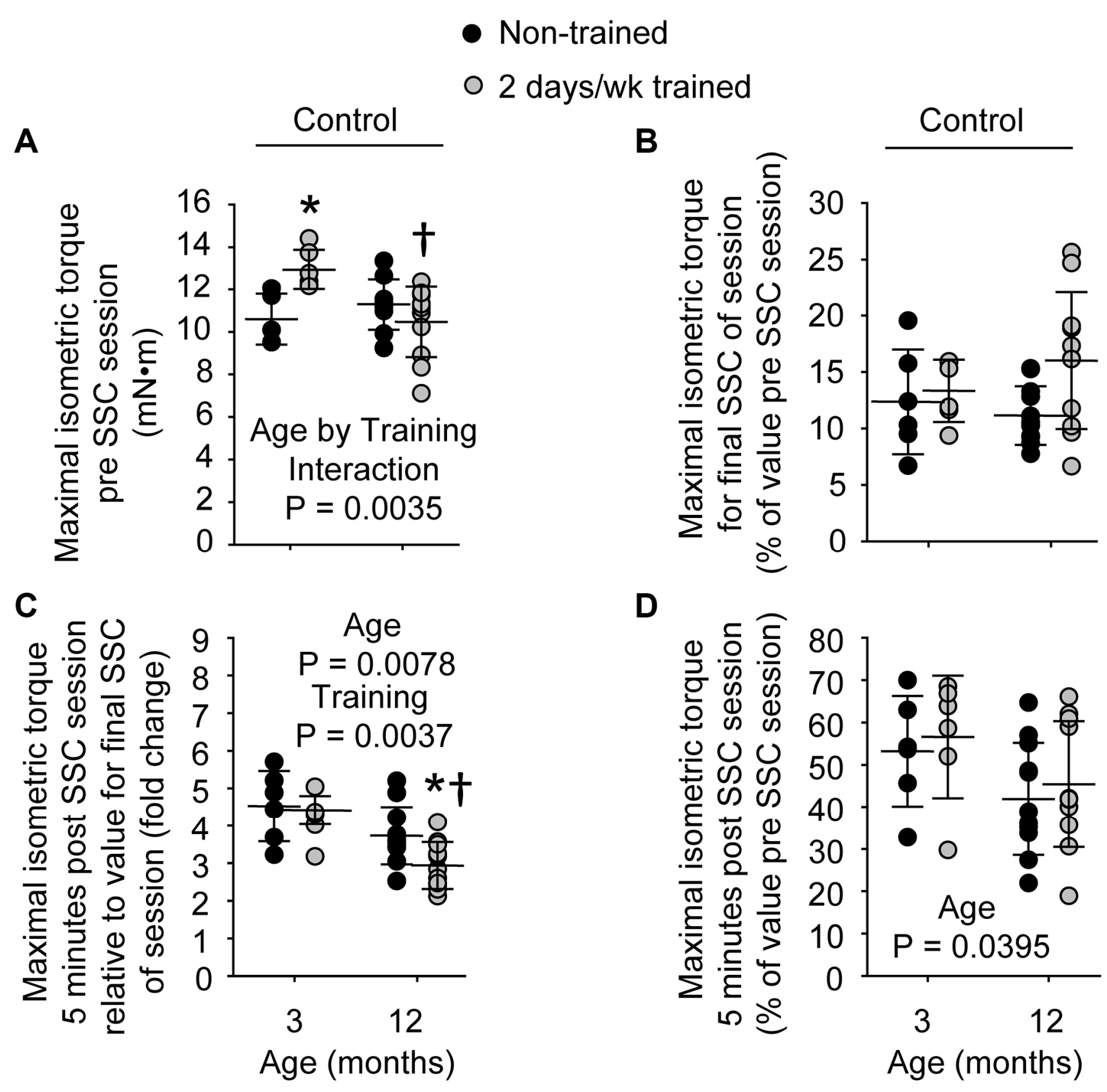

Supplementary Figure 4. Less frequent 2 days per week training enhanced adaptation for pre SSC session maximum isometric torque in 3-month-old control mice with no maladaptation in this measure for 12-month-old control mice. (A) Maximal isometric torque increased with training for 3-month-old mice and remained unaltered for 12-month-old mice. (B) Torque depression by the final session SSC was unaffected by training. (C) Torque recovery in the minutes following SSCs remained unchanged with training at 3 months of age and was reduced with training at 12 months of age. (D) However, overall isometric torque depression which persisted to 5 minutes post SSC session was unaltered by training for both age groups. (B) Sample sizes were $N=5$ to 11 per group. Dots represent raw values. Lines denote means \pm SD. Relevant ANOVA interactions and main effects are noted. *Different from non-trained value; ${ }^{\dagger}$ Different from comparable 3-month-old value, $p<0.05$. 
- Non-trained

O 2 days/wk trained
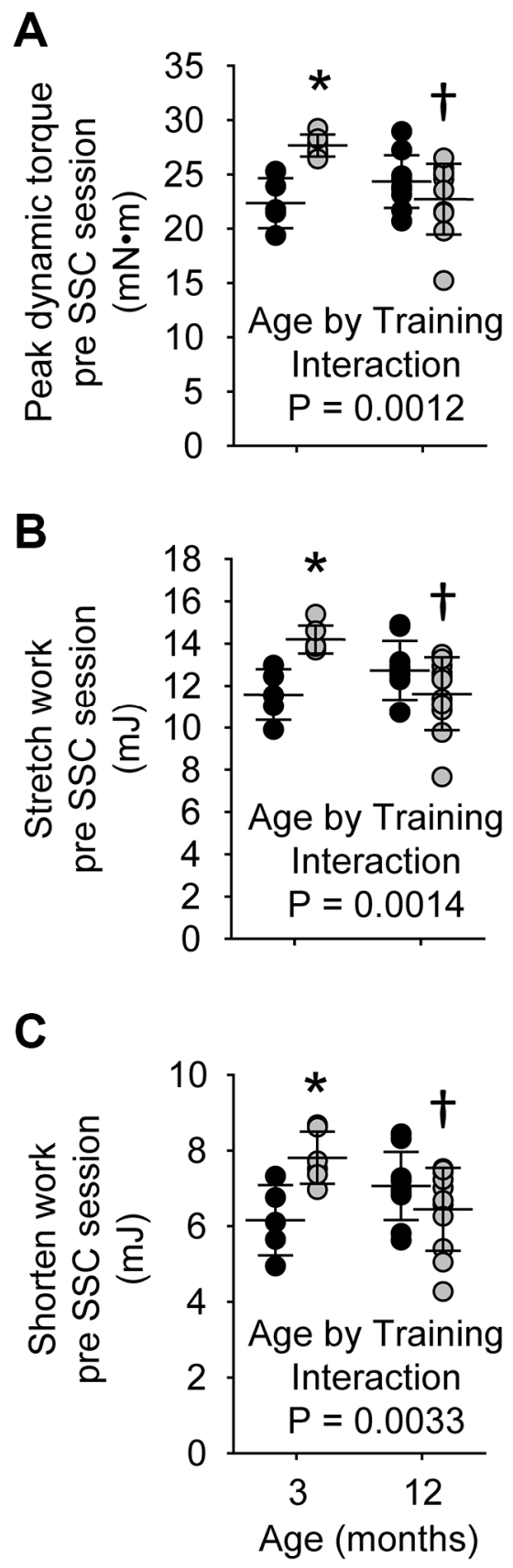

Supplementary Figure 5. Less frequent 2 days per week training enhanced adaptation for several dynamic performance measures in 3-month-old control mice with no maladaptation in 12-month-old control mice. The dynamic measures of (A) peak dynamic torque, (B) stretch work, and (C) shorten work were assessed. Sample sizes were $N=5$ to 11 per group. Dots represent raw values. Lines denote means \pm SD. Relevant ANOVA interactions and main effects are noted. "Different from non-trained value; ${ }^{\dagger}$ Different from comparable 3-month-old value, $P<0.05$. 


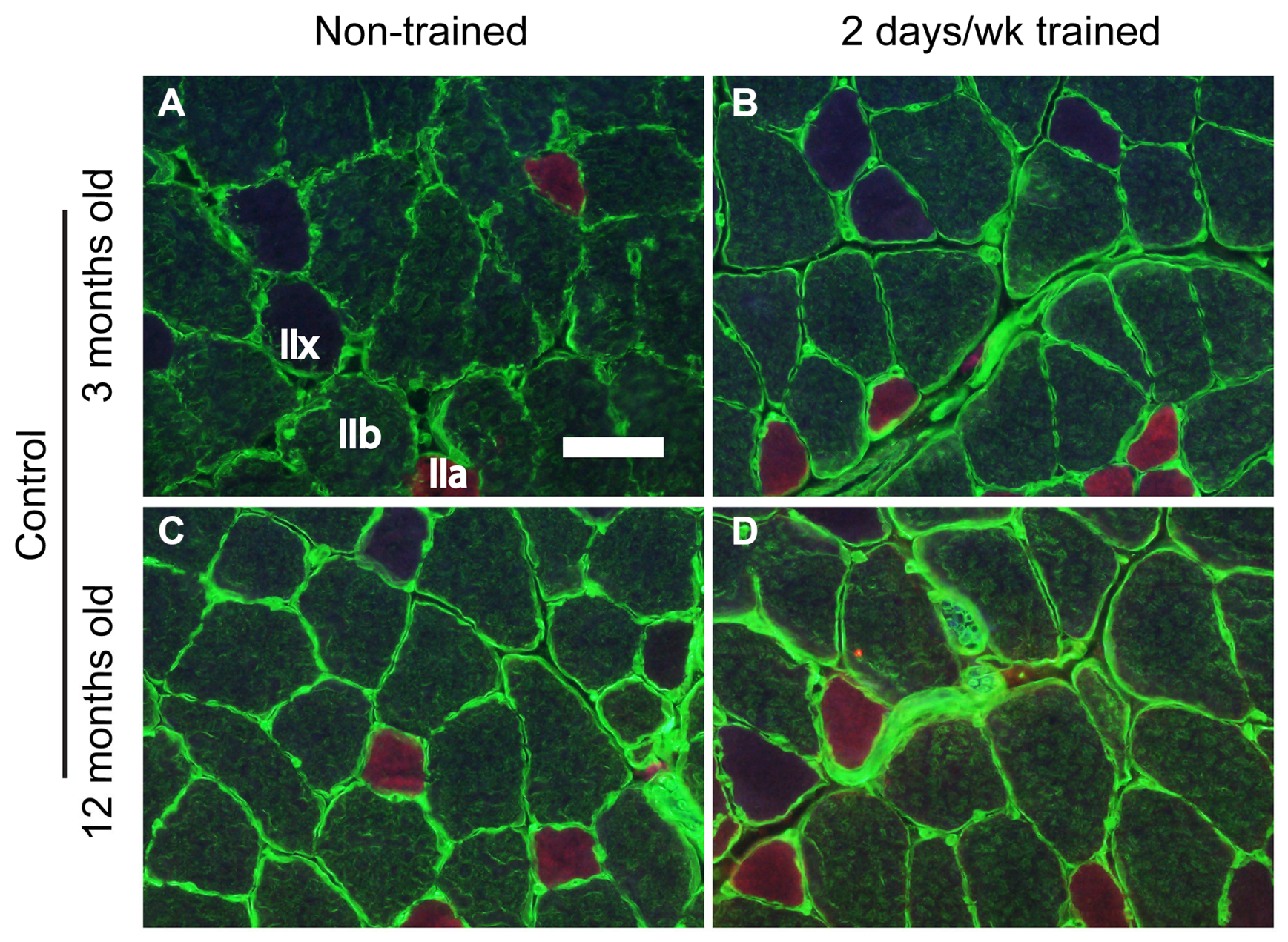

Supplementary Figure 6. Fiber type immunofluorescence staining for muscles of 3-month-old (A, B) and 12-month-old (C, D) control mice following non-training or 2 days per week training. Images depict immunofluorescence for laminin (green) and multiple MHC isoforms - Ilb (green), Ila (red), and IIx (negative for staining). Scale bar $=50 \mu \mathrm{m}$. 
$\begin{array}{ll}- \text { Non-trained } & \text { Ila fiber type - age, } P=0.0294 \\ \circ 2 \text { days/wk trained } & \text { Ilb fiber type-age, } P=0.0315\end{array}$

A

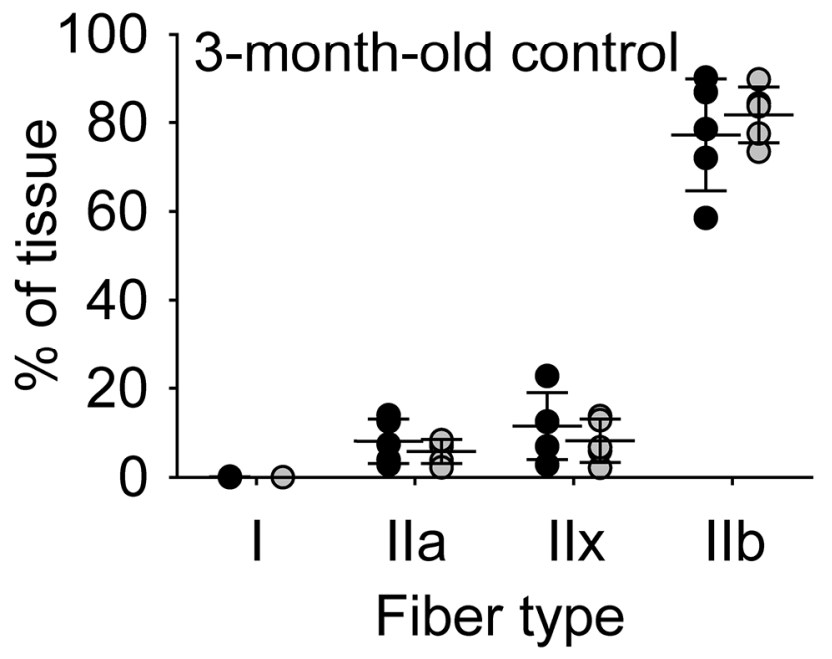

B

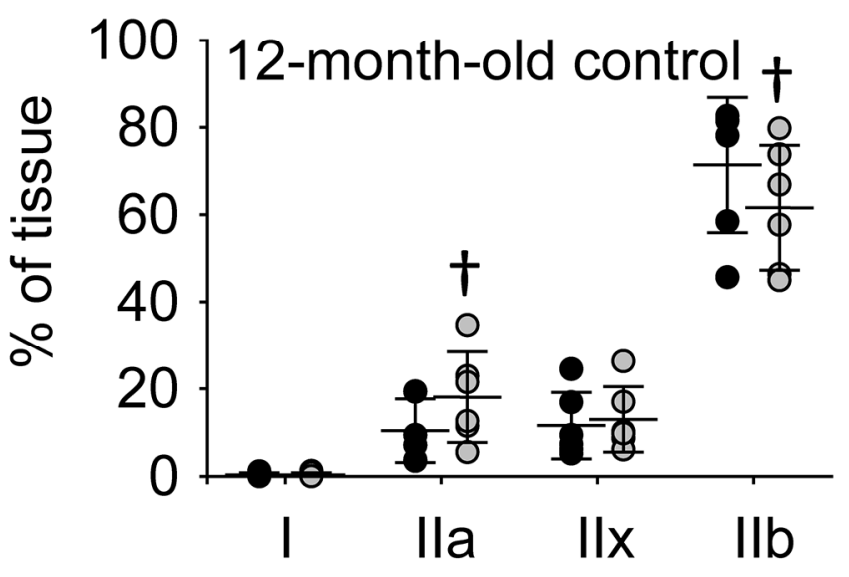

Fiber type

Supplementary Figure 7. Training 2 days per week for control mice had no effect on fiber type distribution relative to nontrained values. Percent of tissue composed of each fiber type for (A) 3-month-old control mice and (B) 12-month-old control mice. Sample sizes were $N=5$ to 6 per group. Dots represent raw values. Lines denote means \pm SD. Relevant ANOVA main effects are noted. ${ }^{\dagger}$ Different from comparable young value, $P<0.05$. 


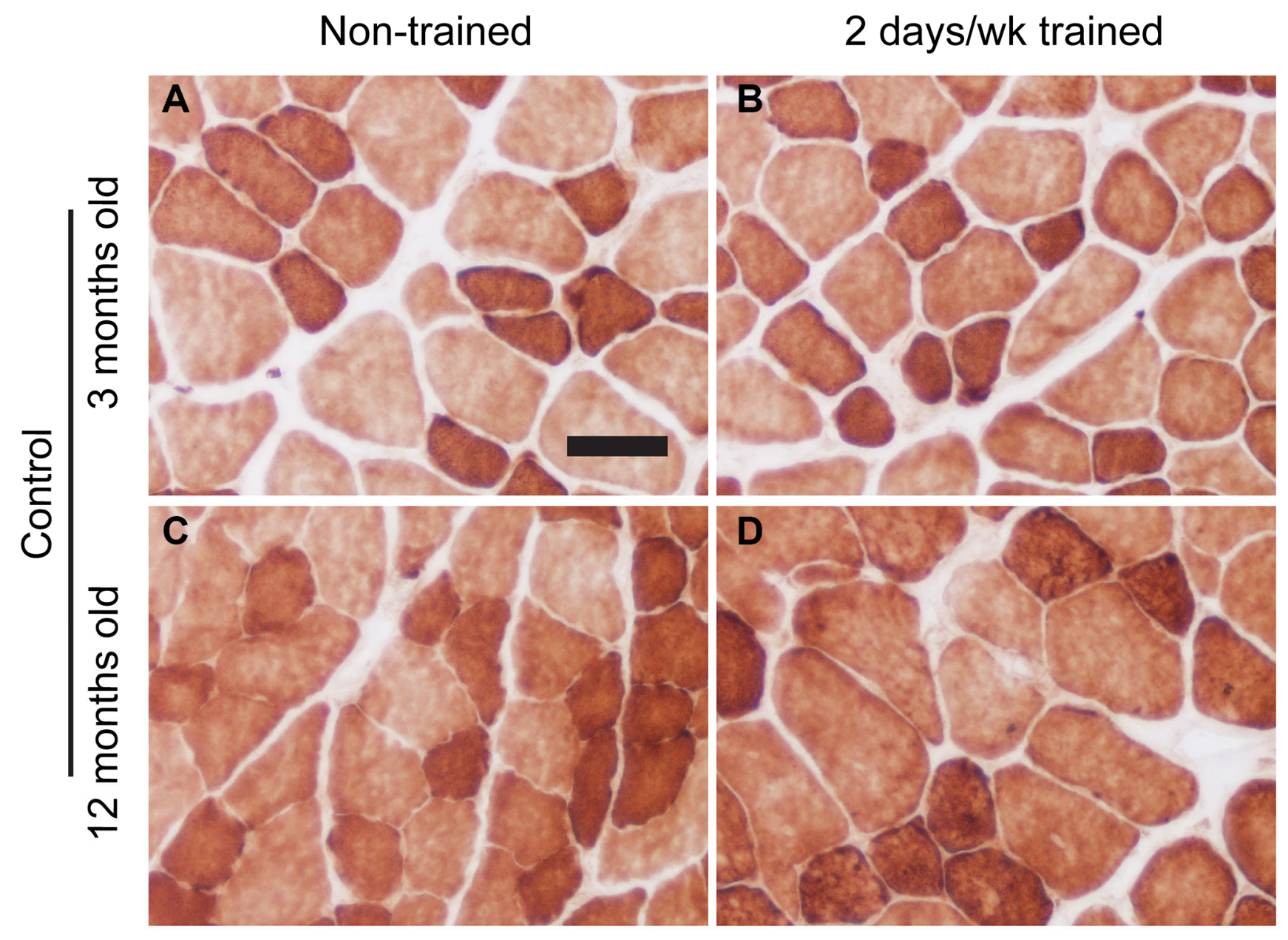

Supplementary Figure 8. COX/SOH labeling of muscles of control mice following $\mathbf{2}$ days per week training. Images depict muscles of 3 month old non-trained (A) and trained (B) muscles and 12 months old non-trained (C) and trained (D) muscles. COX positive muscle fibers dominated displaying light and dark brown staining. No blue (COX deficient/SDH positive) fibers were observed. Scale bar = $50 \mu \mathrm{m}$. 
Non-trained
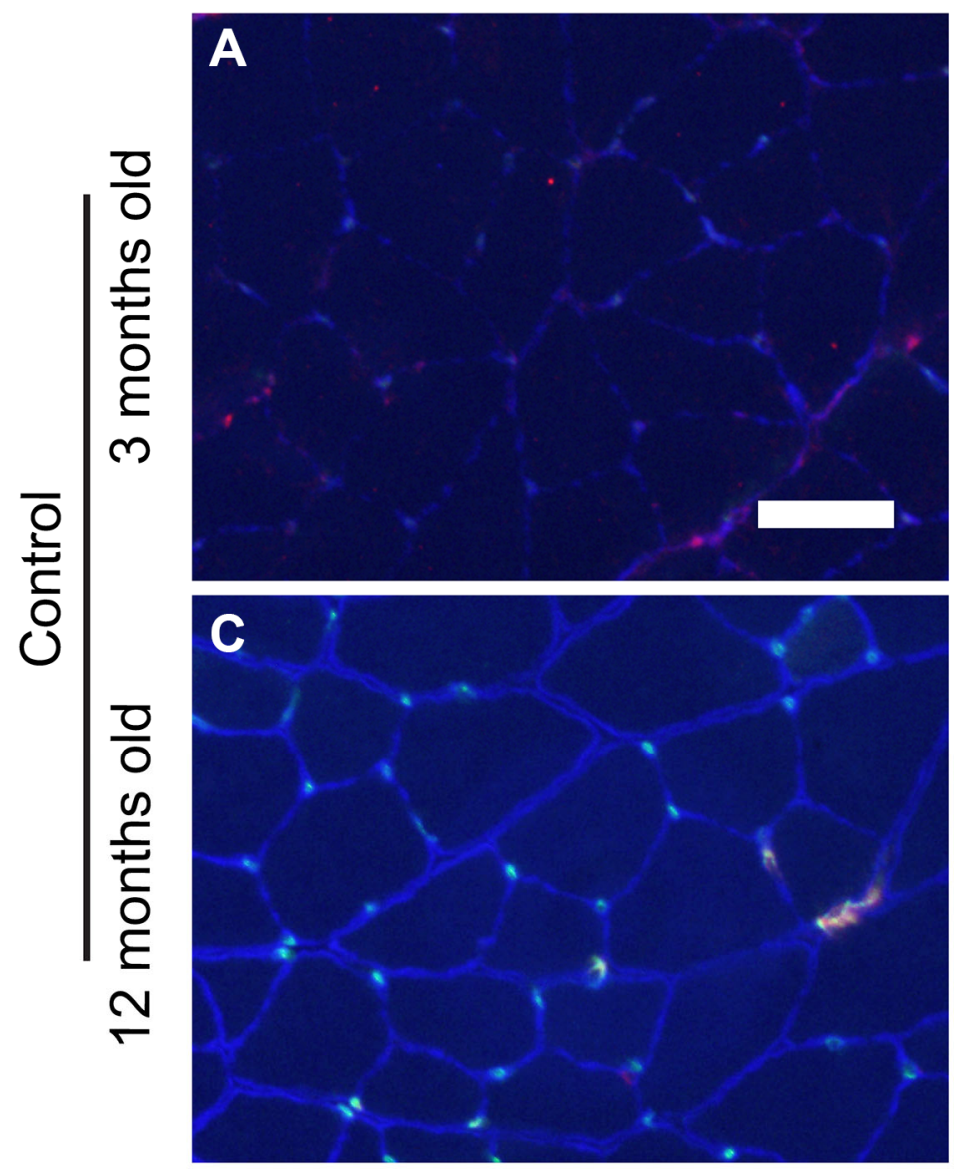

2 days/wk trained
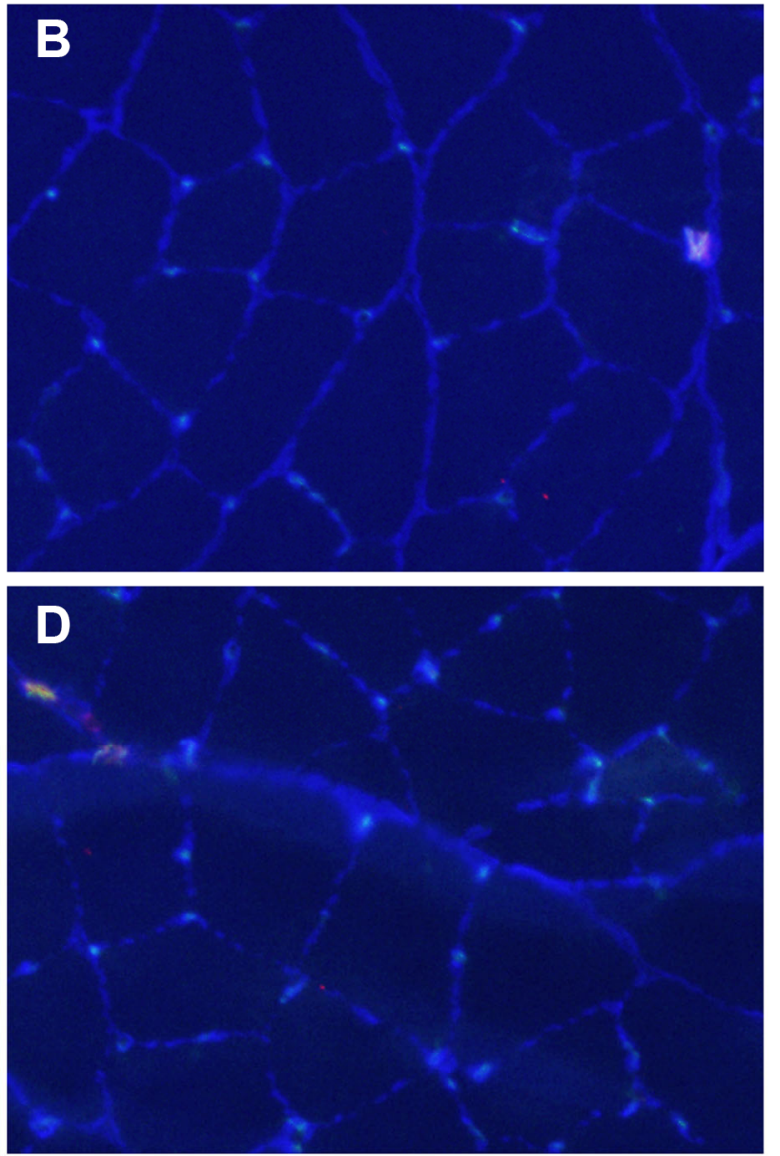

Supplementary Figure 9. Immunofluorescence staining for laminin (blue), CD31 (green), and VCAM-1 (red) in muscles of control mice following 2 days per week training. Images depict muscles of 3 month old non-trained (A) and trained (B) muscles and 12 months old non-trained (C) and trained (D) muscles. Scale bar $=50 \mu \mathrm{m}$.

- Non-trained

$\circ 2$ days/wk trained

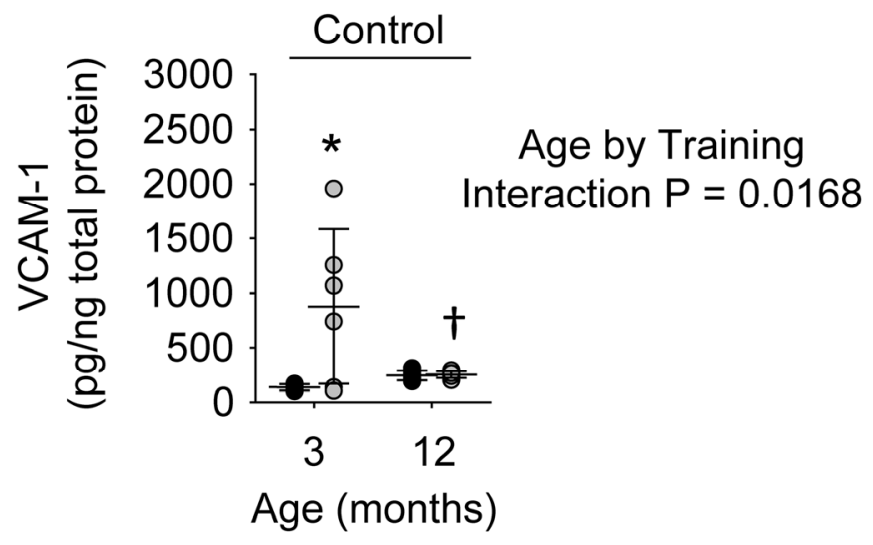

Supplementary Figure 10. VCAM-1 protein levels within muscle homogenates following $\mathbf{2}$ days per week training. Sample sizes were $N=5$ to 6 per group. Dots represent raw values. Lines denote means \pm SD. Relevant ANOVA interaction is noted. "Different from comparable non-trained value, ${ }^{\dagger}$ Different from comparable 3-month-old value, $P<0.05$. 
SSC 1 (first SSC of first set)
SSC 10

(last SSC of first set) (first SSC of last set)

SSC 71
SSC 80

(last SSC of last set)
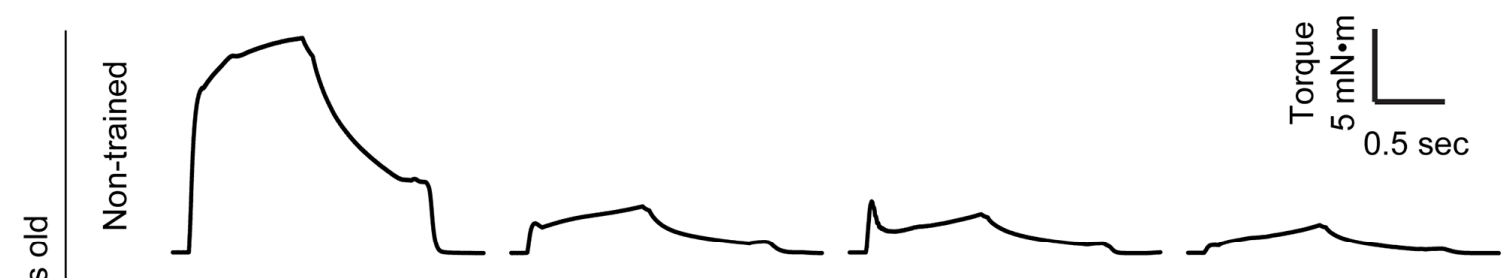

ह


Supplementary Figure 11. Raw torque and position traces during a SSC session for non-trained and 3 day per week trained control mice. Traces for the first and last SSC of the first and last set are displayed. Each session consisted of a total of 8 sets with 10 SSCs per set and 2 minute rest intervals between sets. Arrows indicate when muscle activation began and ended while position traces display the $20^{\circ}$ ankle rotation during each SSC. Each SSC consisted of a consecutive series of isometric, lengthening, shortening, and isometric contractions. 
SSC 1

(first SSC of first set)
SSC 10

(last SSC of first set) (first SSC of last set)
SSC 71

SSC 80

(last SSC of last set)
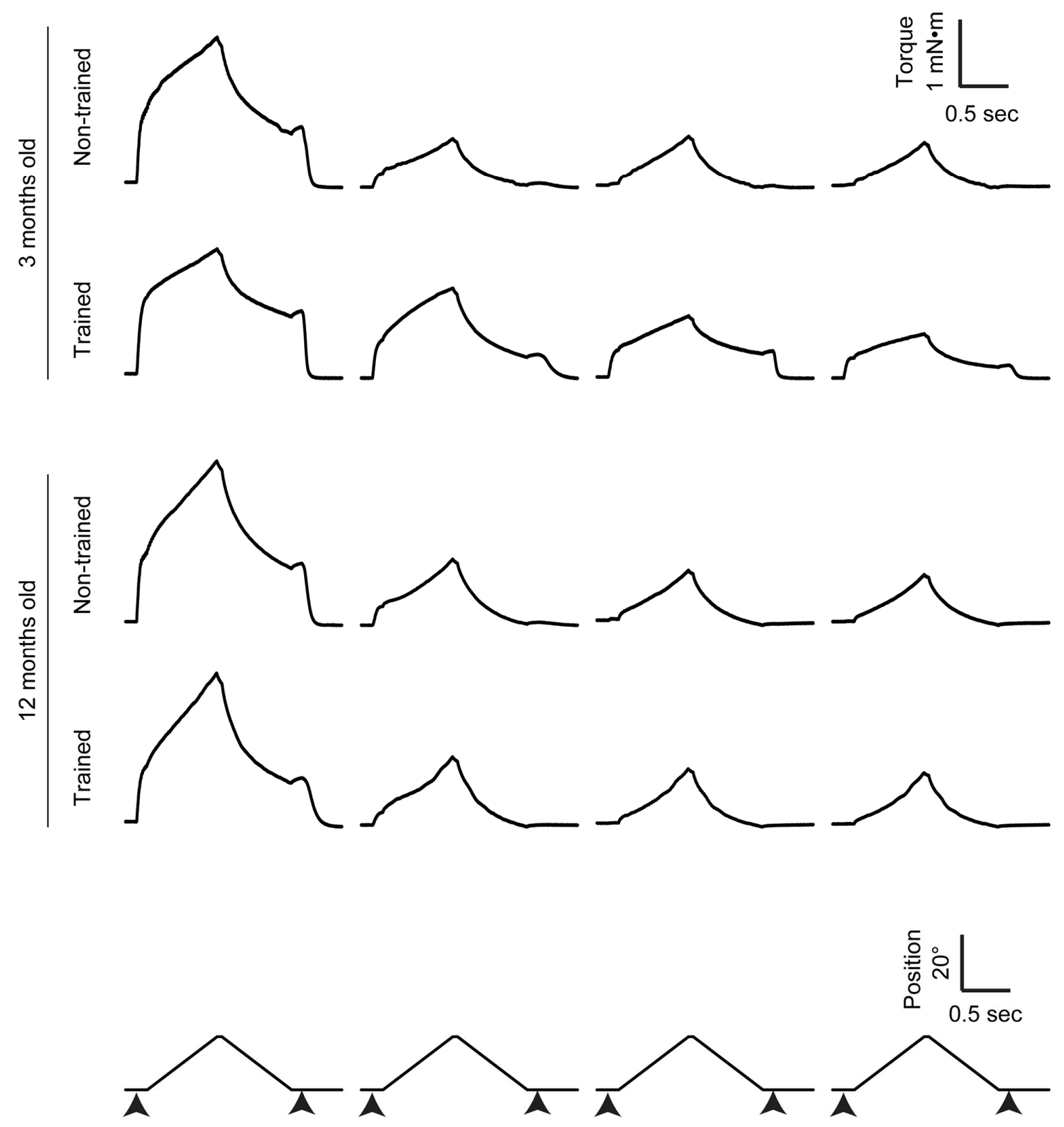

Supplementary Figure 12. Raw torque and position traces during a SSC session for non-trained and 3 day per week trained Snell dwarf mice. Traces for the first and last SSC of the first and last set are displayed. Each session consisted of a total of 8 sets with 10 SSCs per set and 2 minute rest intervals between sets. Arrows indicate when muscle activation began and ended while position traces display the $20^{\circ}$ ankle rotation during each SSC. Each SSC consisted of a consecutive series of isometric, lengthening, shortening, and isometric contractions. 


\section{Supplementary Tables}

Supplementary Table 1. Muscle fiber cross-sectional area categorized by fiber type for control and Snell dwarf mice following 3 days per week training.

\begin{tabular}{|c|c|c|c|c|c|}
\hline & \multicolumn{5}{|c|}{ Muscle fiber cross-sectional area $\mu \mathrm{m}^{2}$} \\
\hline & $\mathbf{I}$ & IIa & IIx & IIb & Total \\
\hline \multicolumn{6}{|l|}{ Control } \\
\hline \multicolumn{6}{|l|}{3 months old } \\
\hline Non-trained & $\mathrm{n} / \mathrm{a}$ & $1060 \pm 138$ & $1773 \pm 880$ & $2504 \pm 274$ & $1939 \pm 91$ \\
\hline 3 days/wk trained & $\mathrm{n} / \mathrm{a}$ & $822 \pm 147$ & $1636 \pm 622$ & $2471 \pm 522$ & $2193 \pm 630$ \\
\hline \multicolumn{6}{|l|}{12 months old } \\
\hline Non-trained & $\mathrm{n} / \mathrm{a}$ & $1114 \pm 375$ & $1540 \pm 711$ & $2676 \pm 525$ & $2179 \pm 469$ \\
\hline 3 days/wk trained & $\mathrm{n} / \mathrm{a}$ & $1005 \pm 650$ & $1433 \pm 414$ & $2189 \pm 233^{*}$ & $1756 \pm 290^{*}$ \\
\hline \multicolumn{6}{|l|}{ Snell } \\
\hline \multicolumn{6}{|l|}{3 months old } \\
\hline Non-trained & $\mathrm{n} / \mathrm{a}$ & $449 \pm 9 *$ & $418 \pm 110^{*}$ & $908 \pm 339$ & $718 \pm 421^{*}$ \\
\hline 3 days/wk trained & $\mathrm{n} / \mathrm{a}$ & $497 \pm 146$ & $423 \pm 150^{\ddagger}$ & $525 \pm 320^{*}$ & $460 \pm 135^{\ddagger}$ \\
\hline \multicolumn{6}{|l|}{12 months old } \\
\hline Non- trained & $436 \pm 178$ & $377 \pm 123^{\ddagger}$ & $440 \pm 59$ & $896 \pm 178^{\ddagger}$ & $657 \pm 231^{*}$ \\
\hline 3 days/wk trained & $540 \pm 81$ & $397 \pm 184$ & $560 \pm 154$ & $778 \pm 187^{\star}$ & $583 \pm 118^{\ddagger}$ \\
\hline
\end{tabular}

Values are expressed as means \pm SD. $n / a$, data not available because of insufficient number of type I muscle fibers observed in samples to determine values. Sample sizes were $N=3$ to 7 per group. ${ }^{*}$ Different from comparable non-trained value. ${ }^{\ddagger}$ Different from comparable control value, $P<0.05$. No differences observed between age groups within genotype.

Supplementary Table 2. Number of muscle fibers per $\mathrm{mm}^{2}$ categorized by fiber type for control and Snell dwarf mice following 3 days per week training.

\begin{tabular}{|c|c|c|c|c|c|}
\hline & \multicolumn{5}{|c|}{ Number of muscle fibers per $\mathbf{m m}^{2}$} \\
\hline & $\mathbf{I}$ & IIa & IIx & IIb & Total \\
\hline \multicolumn{6}{|l|}{ Control } \\
\hline \multicolumn{6}{|l|}{3 months old } \\
\hline Non-trained & $0.0 \pm 0.0$ & $161.3 \pm 57.8$ & $64.6 \pm 24.9$ & $267.5 \pm 84.3$ & $493.3 \pm 25.3$ \\
\hline 3 days/wk trained & $1.7 \pm 3.7$ & $55.6 \pm 32.8$ & $59.8 \pm 33.7$ & $329.3 \pm 43.4$ & $446.3 \pm 93.3$ \\
\hline \multicolumn{6}{|l|}{12 months old } \\
\hline Non-trained & $3.6 \pm 9.4$ & $71.1 \pm 29.3$ & $85.5 \pm 76.7$ & $282.0 \pm 81.4$ & $442.2 \pm 79.2$ \\
\hline 3 days/wk trained & $0.7 \pm 1.7$ & $103.6 \pm 75.6$ & $116.9 \pm 57.5$ & $309.6 \pm 57.0$ & $530.7 \pm 75.9$ \\
\hline \multicolumn{6}{|l|}{ Snell } \\
\hline \multicolumn{6}{|l|}{3 months old } \\
\hline Non-trained & $14.1 \pm 28.1^{\dagger}$ & $289.5 \pm 307.7$ & $523.0 \pm 390.2 *$ & $575.3 \pm 131.2$ & $1401.9 \pm 468.8^{\ddagger}$ \\
\hline 3 days/wk trained & $1.3 \pm 2.8$ & $252.3 \pm 153.9$ & $1078.9 \pm 626.9^{* *}$ & $520.4 \pm 320.1^{*}$ & $1852.9 \pm 481.2^{* *}$ \\
\hline \multicolumn{6}{|l|}{12 months old } \\
\hline Non-trained & $39.3 \pm 45.9^{\dagger \star}$ & $182.8 \pm 150.0$ & $589.3 \pm 301.6^{\ddagger}$ & $572.3 \pm 157.3^{\ddagger}$ & $1383.5 \pm 335.5^{\ddagger}$ \\
\hline 3 days/wk trained & $36.0 \pm 33.1^{\dagger *}$ & $275.3 \pm 206.4$ & $721.3 \pm 442.7$ & $391.6 \pm 162.9$ & $1424.1 \pm 247.5^{\dagger *}$ \\
\hline
\end{tabular}

Values are expressed as means \pm SD. Sample sizes were $N=4$ to 7 per group. ${ }^{*}$ Different from comparable non-trained value. ${ }^{\dagger}$ Different from comparable 3-month -old value. ${ }^{\ddagger}$ Different from comparable control value, $P<0.05$. 
Supplementary Table 3. Percentage of muscle fibers with dark brown staining (COX ${ }^{++}$fibers) for control and Snell dwarf mice following 3 days per week training.

\%Cox $^{++}$fibers

\section{Control}

3 months old

Non-trained

$41.2 \pm 8.1$

3 days/wk trained

$45.2 \pm 13.7$

12 months old

Non-trained

$42.3 \pm 11.5$

3 days/wk trained

$37.2 \pm 14.1$

\section{Snell}

3 month s old

Non-trained

$45.7 \pm 15.0$

3 days/wk trained

$39.1 \pm 9.8$

12 months old

Non-trained

$47.3 \pm 8.6$

3 days/wk trained

$41.0 \pm 9.9$

Values are expressed as means \pm SD. Sample sizes were $N=5$ to 7 per group. No significant differences were observed.

Supplementary Table 4. Measures of total $\mathrm{CD} 31^{+}$nodes and VCAM-1+CD31+ nodes for control and Snell dwarf mice following 3 days per week training.

\begin{tabular}{|c|c|c|}
\hline & $\begin{array}{c}\text { Total CD31 } \\
\text { nodes }^{+} \mathbf{m m}^{2}\end{array}$ &  \\
\hline \multicolumn{3}{|l|}{ Control } \\
\hline \multicolumn{3}{|l|}{3 months old } \\
\hline Non-trained & $587 \pm 86$ & $96 \pm 96$ \\
\hline 3 days/wk trained & $656 \pm 268$ & $85 \pm 47$ \\
\hline \multicolumn{3}{|l|}{12 months old } \\
\hline Non-trained & $759 \pm 107$ & $92 \pm 73$ \\
\hline 3 days/wk trained & $840 \pm 214$ & $112 \pm 55$ \\
\hline \multicolumn{3}{|l|}{ Snell } \\
\hline \multicolumn{3}{|l|}{3 months old } \\
\hline Non-trained & $866 \pm 365^{\ddagger}$ & $126 \pm 70$ \\
\hline 3 days/wk trained & $852 \pm 129$ & $114 \pm 36$ \\
\hline \multicolumn{3}{|l|}{12 months old } \\
\hline Non-trained & $1040 \pm 244$ & $197 \pm 107$ \\
\hline 3 days/wk trained & $1128 \pm 238$ & $305 \pm 214^{\dagger *}$ \\
\hline
\end{tabular}

Values are expressed as means \pm SO. Sample sizes were $N=4$ to 7 per group. ${ }^{\dagger}$ Different from comparable 3-month-old value. ${ }^{\ddagger}$ Different from comparable control value, $P<0.05$. 
Supplementary Table 5. Body weight, tibial length, muscle mass, and muscle quality data for control mice following 2 days per week training.

\begin{tabular}{|c|c|c|c|c|c|c|c|c|c|c|c|}
\hline & \multirow[b]{2}{*}{$\begin{array}{l}\text { Body weight } \\
\text { (g) }\end{array}$} & \multirow[b]{2}{*}{$\begin{array}{l}\text { Tibial length } \\
\text { (mm) }\end{array}$} & \multicolumn{4}{|c|}{ Muscle mass (mg) } & \multicolumn{4}{|c|}{ Nonmalized muscle mass (mg/mm) } & \multirow{2}{*}{$\begin{array}{l}\text { Muscle } \\
\text { qualiry } \\
(\mathrm{mN} \cdot \mathrm{m} / \\
\mathrm{mg} / \mathrm{mm})\end{array}$} \\
\hline & & & Gastrocnemius & Plantaris & Soleus & $\begin{array}{c}\text { Plamarflexor } \\
\text { group }\end{array}$ & Gastrocnemius & Plantaris & Soleus & $\begin{array}{c}\text { Plantarflexor } \\
\text { group }\end{array}$ & \\
\hline \multicolumn{12}{|l|}{ Control } \\
\hline \multicolumn{12}{|l|}{3 months old } \\
\hline Non-trained & $31.8 \pm 2.5$ & $18.6 \pm 0.4$ & $132.4 \pm 17.8$ & $18.6 \pm 2.0$ & $9.5 \pm 1.0$ & $160.5 \pm 19.9$ & $7.10 \pm 0.84$ & $1.00 \pm 0.09$ & $0.51 \pm 0.05$ & $8.61 \pm 0.93$ & $1.24 \pm 0.16$ \\
\hline 2 days/wk trained & $32.1 \pm 3.4$ & $18.6 \pm 0.2$ & $135.5 \pm 13.8$ & $18.3 \pm 2.9$ & $8.8 \pm 2.7$ & $162.6 \pm 15.7$ & $7.29 \pm 0.67$ & $0.99 \pm 0.16$ & $0.47 \pm 0.14$ & $8.75 \pm 0.76$ & $1.48 \pm 0.05$ \\
\hline \multicolumn{12}{|l|}{12 months old } \\
\hline Non-trained & $42.2 \pm 6.3^{\dagger}$ & $19.0 \pm 0.4^{\dagger}$ & $129.4 \pm 7.6$ & $17.3 \pm 2.3$ & $9.2 \pm 0.9$ & $155.9 \pm 9.8$ & $6.80 \pm 0.40$ & $0.91 \pm 0.11$ & $0.48 \pm 0.04$ & $8.19 \pm 0.49$ & $1.39 \pm 0.19$ \\
\hline 2 days/wk trained & $43.1 \pm 4.4^{\dagger}$ & $19.0 \pm 0.3^{\dagger}$ & $123.7 \pm 12.5$ & $16.0 \pm 2.0^{\dagger}$ & $8.7 \pm 1.0$ & $148.4 \pm 14.5$ & $6.50 \pm 0.19^{\dagger}$ & $0.84 \pm 0.03^{\dagger}$ & $0.45 \pm 0.01$ & $7.80 \pm 0.71^{\dagger}$ & $1.34 \pm 0.16$ \\
\hline
\end{tabular}

Values are expressed as means \pm SD. Sample sizes were $N=5$ to 10 per group. ${ }^{*}$ Different from comparable non-trained value. ${ }^{+}$Different from comparable 3-month-old value, $P<0.05$.

Supplementary Table 6. Muscle fiber cross-sectional area categorized by fiber type for control mice following 2 days per week training.

\begin{tabular}{|c|c|c|c|c|c|}
\hline & \multicolumn{5}{|c|}{ Muscle fiber cross-sectional area $\mu \mathrm{m}^{2}$} \\
\hline & $\mathbf{I}$ & IIa & IIx & IIb & Total \\
\hline \multicolumn{6}{|l|}{ Control } \\
\hline \multicolumn{6}{|l|}{3 months old } \\
\hline Non-trained & $\mathrm{n} / \mathrm{a}$ & $961 \pm 330$ & $1266 \pm 342$ & $2660 \pm 297$ & $2122 \pm 117$ \\
\hline 2 days/wk trained & $\mathrm{n} / \mathrm{a}$ & $988 \pm 238$ & $1647 \pm 247$ & $3063 \pm 436$ & $2540 \pm 219$ \\
\hline \multicolumn{6}{|l|}{12 months old } \\
\hline Non-trained & $\mathrm{n} / \mathrm{a}$ & $1166 \pm 279$ & $1647 \pm 506$ & $2639 \pm 265$ & $2180 \pm 182$ \\
\hline 2 days/wk trained & $\mathrm{n} / \mathrm{a}$ & $1134 \pm 326$ & $1454 \pm 141$ & $2557 \pm 667$ & $1931 \pm 565^{\dagger}$ \\
\hline
\end{tabular}

Values are expressed as means \pm SD. $n / a$, data not available because of insufficient number of type I muscle fibers observed in samples to determine values. Sample sizes were $N=5$ to 6 per group. ${ }^{\dagger}$ Different from comparable 3 -month-old value, $P<0.05$.

Supplementary Table 7. Number of muscle fibers per $\mathrm{mm}^{2}$ categorized by fiber type for control mice following 2 days per week training. Values are expressed as means \pm SD.

\begin{tabular}{|c|c|c|c|c|c|}
\hline & \multicolumn{5}{|c|}{ Number of muscle fibers per $\mathrm{mm}^{2}$} \\
\hline & $\mathbf{I}$ & IIa & IIx & IIb & Total \\
\hline \multicolumn{6}{|l|}{ Control } \\
\hline \multicolumn{6}{|l|}{3 months old } \\
\hline Non-trained & $0.0 \pm 0.0$ & $79.3 \pm 35.5$ & $82.7 \pm 36.7$ & $295.1 \pm 69.8$ & $457.2 \pm 27.2$ \\
\hline 2 days/wk trained & $0.0 \pm 0.0$ & $58.5 \pm 21.0$ & $47.4 \pm 24.2$ & $272.9 \pm 56.7$ & $378.8 \pm 27.1$ \\
\hline \multicolumn{6}{|l|}{12 months old } \\
\hline Non-trained & $1.0 \pm 1.6$ & $87.2 \pm 52.5$ & $67.1 \pm 33.3$ & $276.4 \pm 80.0$ & $431.6 \pm 28.3$ \\
\hline 2 days/wk trained & $1.6 \pm 3.8$ & $180.0 \pm 139.1$ & $87.9 \pm 43.7$ & $244.9 \pm 43.4$ & $514.3 \pm 136.5^{\dagger}$ \\
\hline
\end{tabular}

Sample sizes were $N=5$ to 6 per group. ${ }^{\dagger}$ Different from comparable 3-month-old value, $P<0.05$. 
Supplementary Table 8. Percentage of muscle fibers with dark brown staining (COX ${ }^{++}$fibers) for control and Snell dwarf mice following 2 days per week training.

$\% \mathrm{Cox}^{++}$fibers

\section{Control}

3 months old

Non-trained

3 days/wk trained

$29.9 \pm 10.2$

12 months old

Non-trained

$33.1 \pm 4.6$

3 days/wk trained

$39.0 \pm 11.0$

$42.1 \pm 14.2$

Values are expressed as means \pm SD. Sample sizes were $N=5$ to 6 per group. No significant differences were observed.

Supplementary Table 9. Measures of total CD31 ${ }^{+}$nodes and $\mathrm{VCAM}-1^{+} \mathrm{CD} 31^{+}$nodes for control mice following 2 days per week training.

\begin{tabular}{lcc}
\hline Control & Total CD31 ${ }^{+} / \mathbf{m m}^{2}$ & $\begin{array}{c}\mathbf{V C A M - 1}^{+} \mathbf{C D 3 1}^{+} \\
\text {nodes }^{+} \mathbf{m m}^{\mathbf{2}}\end{array}$ \\
3 months old & & \\
$\quad$ Non-trained & $632 \pm 205$ & $138 \pm 95$ \\
3 days/wk trained & $627 \pm 260$ & $55 \pm 49$ \\
12 months old & & \\
$\quad$ Non- trained & $688 \pm 166$ & $92 \pm 87$ \\
3 days/wk trained & $840 \pm 68$ & $96 \pm 68$ \\
\hline
\end{tabular}

Values are expressed as means \pm SD. Sample sizes were $N=5$ to 6 per group. No significant differences observed, $P<0.05$. 